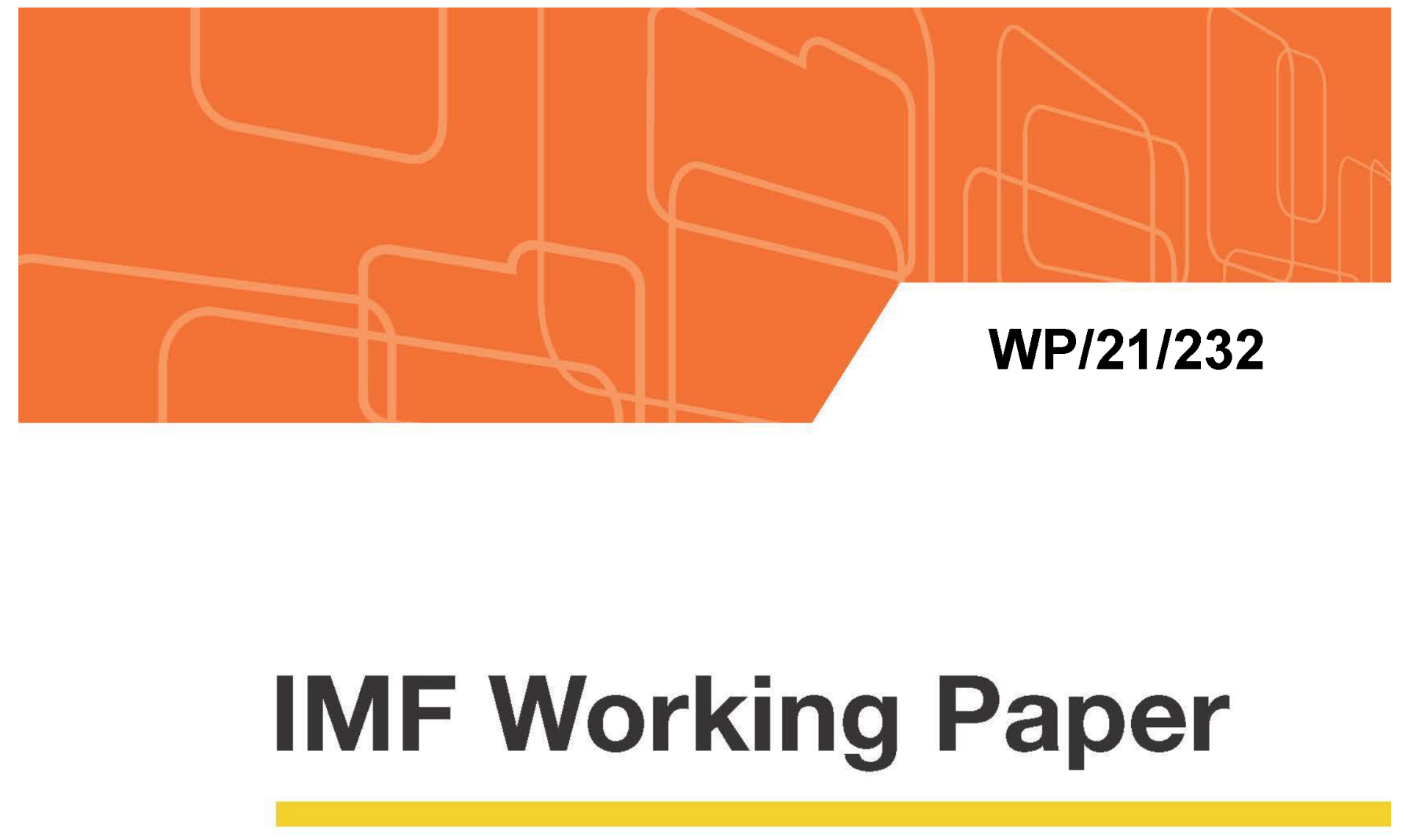

\title{
Assessing Chile's Pension System: Challenges and Reform Options
}

Christopher Evans and Samuel Pienknagura

IMF Working Papers describe research in progress by the author(s) and are published to elicit comments and to encourage debate. The views expressed in IMF Working Papers are those of the author(s) and do not necessarily represent the views of the IMF, its Executive Board, or IMF management.

$$
\text { I N T E R N A T I O N A L M O N E T A R Y F U N D }
$$




\title{
IMF Working Paper
}

WHD

\section{Assessing Chile's Pension System: Challenges and Reform Options \\ Prepared by Christopher Evans and Samuel Pienknagura}

Authorized for distribution by Luca Antonio Ricci

September 2021

IMF Working Papers describe research in progress by the author(s) and are published to elicit comments and to encourage debate. The views expressed in IMF Working Papers are those of the author(s) and do not necessarily represent the views of the IMF, its Executive Board, or IMF management.

\begin{abstract}
Chile's pension system came under close scrutiny in recent years. This paper takes stock of the adequacy of the system and highlights its challenges. Chile's defined contribution system was quite influential when introduced, and was taken as an example by other countries. However, it is now delivering low replacement rates relative to OECD peers, as its parameters did not adapt over time to changing demographics and global returns, while informality persists in the labor market. In the absence of reforms, the system's inability to deliver adequate outcomes for a large share of participants will continue to magnify, as demographic trends and low global interest rates will continue to reduce replacement rates. In addition, recent legislation allowing for pension savings withdrawals to counter the effects from the COVID-19 pandemic, is projected to further reduce replacement rates and increase fiscal costs. A substantial improvement in replacement rates is feasible, via a reform that raises contribution rates and the retirement age, coupled with policies that increases workers' contribution density.
\end{abstract}

JEL Classification Numbers: D14, H30, H55

Keywords: Chile, COVID-19, Fiscal Costs, Pensions, Replacement Rates.

Author’s E-Mail Address: Cevans@imf.org; Spienknagura@imf.org

We thank Luca Antonio Ricci for his support and valuable inputs throughout this project. The paper also benefitted from helpful comments by Boele Bonthuis, Csaba Feher, Chiara Fratto, Metodij Hadzi-Vaskov, José Torres, Ana Corbacho, and staff from the Superintendencia de Pensiones and the Ministry of Finance of Chile. 


\section{Contents}

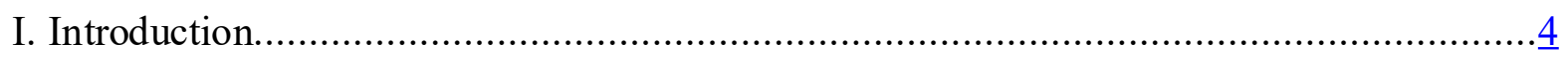

II. The Pre-Pandemic State of the Pension System ………............................................. 1

III. The Pension System in the Aftermath of Withdrawals ............................................ 16

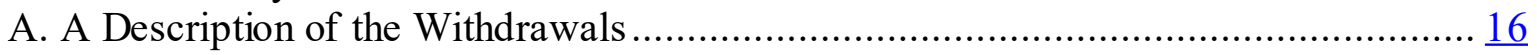

B. Assessing the Impact of Withdrawals ............................................................. 21

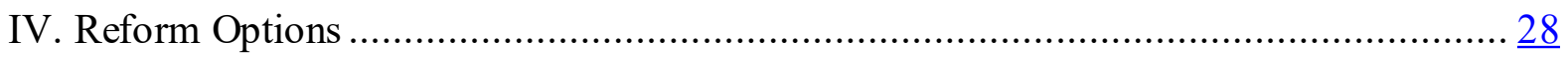

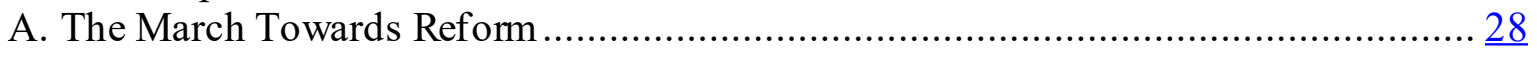

B. Quantifying the Impact of Reform Proposals …………….................................. $\underline{30}$

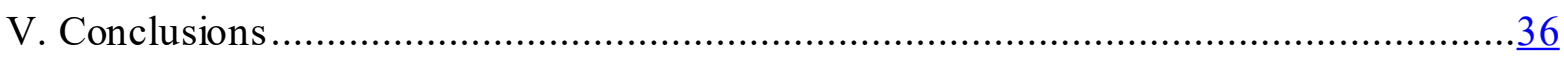

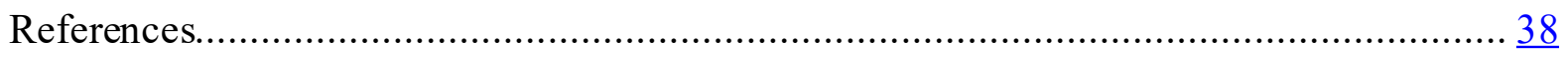

Annex I. The Structure of the Chilean Pension System.................................................. 40

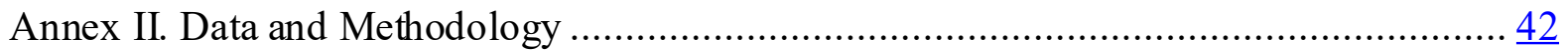

A. Intemational data.......................................................................................... 42

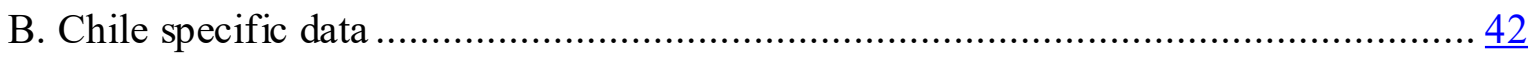

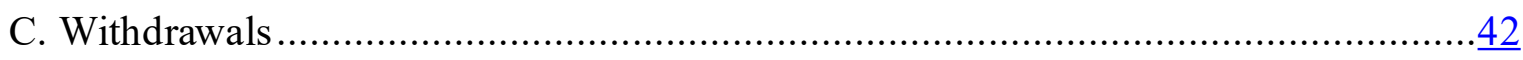

D. Projecting Pensions: Methodology and Assumptions ………………………….... 42

Annex III. Expected Replacement rates under the altemative scenario .............................. $\underline{46}$

Annex IV. Individual reform scenarios................................................................. 4 


\section{INTRODUCTION}

Initially praised for its positive impact on private savings, Chile's pension system has come under scrutiny in recent years. Chile was the first country to replace a traditional pay-as-you-go (PAYG) system that offered a defined benefit with a fully funded pension system based on a defined contribution that financed individual capital accounts managed by private fund managers (AFPs). The switch was motivated by efficiency and fiscal concerns, ${ }^{1}$ and "by a desire to reduce the role of the government in economic affairs" (OECD, 1998). Early assessments linked the new pensions system with growing private savings and with the development of local financial markets (Roldos, 2007). The apparent success of the Chilean experience sparked a wave of pension reform in Latin America and other emerging markets. As the system matured, however, its limitations became apparent. First, to encourage participation in the new system, mandatory contribution rates were set at relatively low levels. This, in turn, resulted in low replacement rates relative to initial expectations at the time of the transition and by international standards (Barr and Diamond, 2016). In addition, informality and self-employment, together with low job tenure, resulted in relatively low contribution densities and coverage.

The system's limitations, which are expected to become even more apparent in the future, put pension reform at the center of the political debate in recent years. The introduction of the solidarity pillar in 2008, marked the beginning of a reform agenda aimed at improving the system's fairness and overall functioning, which continues to this day, as witnessed by the 50 percent increase in the minimum pension introduced in December 2019. Moreover, the extraordinary measures taken in 2020 to support households during the COVID crisis, which included allowing individuals contributing to the pension system to withdraw funds from their pension account balance, added to the challenges. The resulting three rounds of withdrawal of assets amounted to 19 percent of GDP and the first two withdrawals resulted in about 30 percent of individuals who withdrew funds depleting their pension accounts (as of early-May 2021).

This paper contributes to the debate around the adequacy of Chile's pensions system and reform options, by leveraging publicly available data to project key outcomes of the system under different scenarios. The analysis focuses mainly on those who are currently contributing to the system and who are expected to retire in the future. Thus, it provides a prospective view of Chile's pension system. In particular, the paper assesses the impact of the COVID-related withdrawals on expected replacement rates and fiscal costs and explores reform options affecting future retirees. The paper extends the analysis of the Selected Issues

\footnotetext{
${ }^{1}$ Soto (2007) high lights that in 1980 the Chilean pension system was paying more in benefits than it was receiving in contributions. Moreover, the old system, which was a collection of different pension regimes, was said to be poorly administered and inefficient(Edwards, 1996).
} 
Paper that accompanied the IMF Country Report No. 21/84 by providing the latest data on pension withdrawals, analysis of the impact of the $3^{\text {rd }}$ withdrawal on expected replacement rates and fiscal costs, and further detailing the effect of different pension reform options on the Chilean pension system.

The paper shows that, prior to the COVID-related withdrawals, Chile's pension system yielded replacement rates that compared unfavorably to OECD peers, although there is a large degree of heterogeneity across cohorts and income groups, and replacement rates appear to be larger compared to what a PAYG would have produced. Chile's relatively low average replacement rate reflects policy parameters (contribution rates and retirement age) that were originally set to yield higher replacement rates but have not kept up with higher life expectancy, declining interest rates, and a low contribution density, and which are expected to lead to declining replacement rates for younger cohorts. In fact, Chile has a lower effective contribution rate than most OECD countries. Furthermore, replacement rates would be even lower in absence of the solidarity pillar introduced in 2008 , which sets a pension floor for those in the bottom 60 percent of the income distribution. Indeed, lowincome pensioners, who benefit from the solidarity pillar, have relatively high replacement rates compared to the country average. However, replacement rates would have been significantly lower under a PAYG system, especially for men.

The withdrawals are expected to further deteriorate the system's outcomes - for current affiliates, the average withdrawal is projected to result in a 7 percent decline in pension at retirement. The three rounds of withdrawals, which amounted to 19 percent of 2020 GDP by early-May 2021, are expected to reduce the self-financed portion of pensions of current affiliates by 21 percent, on average (i.e. in the absence of any compensating government support). However, this impact will be partly offset by an increase in the government-funded pension supplement, triggered by the reduction in self-funded pension, leading to a reduction in total pensions of about 7 percent and a decline in the average expected replacement rate, from 37 percent to 35 percent.

This buffering role of the solidarity pillar will lead to an additional fiscal cost estimated at a net present value of about 6 percent of GDP in 2020. The withdrawals will affect costs associated to the solidarity pillar by increasing (i) the number of recipients of the pension supplement (to the extent that some pensioners are expected to fall into the lower 60 percent of the income distribution) and (ii) the amount received by each recipient. The sum of these effects will lead to a gradual increase in the additional fiscal costs which are expected to peak in 2060 between 0.09 and 0.17 percent of GDP depending on assumptions. The increasing profile of additional fiscal costs would be equivalent, in net present value, to a one-off fiscal cost of between 3 and 6 percent of GDP in 2020. Of course, future increases in the solidarity contributions would increase such a cost. 
Turning to reforms, our projections show that increases in contribution rates, retirement age, and contribution densities could lead to sig nificant improvements in expected replacement rates. Moreover, many combinations of reforms that adjust several parameters in tandem can lead to sizeable increases in expected replacement rates. For example, a reform package that simultaneously increases the contribution rate to 16 percent, the retirement age for men and women to 67 and improved the contribution density to 70 percent would raise the average expected replacement rate to 50 percent from 35 percent, for the average worker; for young people (who have more time to benefit from the changes) the effect would be much larger: the expected replacement rates would increase to 70 percent for males aged 20-25 and close to 60 percent for females aged 20-25. To be sure, our framework does not consider the behavioral response on the part of workers in response to changes in the parameters of the system. For example, an increase the contribution rate may lead to decrease in the contribution density by means of an increase in informality. Thus, some of the results of our policy experiments can be interpreted as upper bounds to the potential benefits. In practice, reforms may need to be phased-in to address political economy and labor market considerations.

Finally, the analysis highlights the heterogeneous impact of different reforms across cohorts and showcases the importance of adapting the system's parameters to demographic trends and to global returns. Changes to contribution rates and policies that increase the contribution density have a large positive ef fect on expected replacement rates of younger cohorts, while leaving expected replacement rates of older cohorts virtually unchanged. Changes on the retirement age, on the other hand, results in non-negligible improvements in expected replacement rates for all cohorts. Importantly, the resiliency of the system can be improved by allowing periodic revisions to key parameters to reflect secular changes in life expectancy and global financial conditions.

The rest of this paper is organized as follows. Section II describes the state of the pension system under current legislation prior to the withdrawals and benchmarks the system's outcomes relative to Latin American and OECD peers. Then, using data from the pension supervisory agency, it projects replacement rates and fiscal costs pre-withdrawals. Section III describes the withdrawals and quantifies their impact on expected replacement rates and expected fiscal costs. ${ }^{2}$ Section IV studies the impact of different pension reform avenues on replacement rates and on fiscal costs taking into account the effect of withdrawals. Finally, Section V concludes.

\footnotetext{
${ }^{2}$ For an analysis of the macroeconomic consequences of pension reform, see Sa ntoro (2017).
} 


\section{The Pre-Pandemic State of the Pension System}

Under current legislation ${ }^{3}$ and prior to the pandemic, replacement rates in Chile were comparatively lower than in peers. Comparing replacement rates is far from a straightforward task because they are very sensitive to assumptions. Moreover, compared to the Chilean system, some systems (especially PAYG) provide pension payments only to individuals with a minimum number of years of contribution, which further complicates international comparisons as many of the people who receive a pension under the Chilean system would not in other systems These caveats notwithstanding, both regional and global comparisons show that Chile's pension system yields relatively low replacement rates. Altamirano et al. 2018 show that, at 38 percent, the expected replacement rate for an average Chilean worker retiring in 2015 was lower than in the average LAC country. ${ }^{4}$ OECD analysis shows a similar picture - the OECD's pension model projects that a Chilean retiring around 2060 would have a replacement rate of about 30 (lower than the above one due to future demographics and possibly different assumptions about future returns), which is 20 percentage points below the OECD average (Figure 1). In addition to highlighting cross country differences, the analysis in Altamirano et al. 2018 and in OECD shows that replacement rates are expected to decline over time due to a number of factors that are described below.

A combination of factors related to the design of the system, the functioning of Chile's labor markets, demographic trends and global macroeconomic are behind the low replacement rates. ${ }^{5}$ The first factor is the low contribution rate. Chile's effective contribution rate is lower than most OECD countries (Figure 2, Panel A). Contribution rates were initially set at relatively low levels to encourage workers to transition from the PAYG system to the privately funded system and have not been increased since. However, as the first cohorts under the new system started retiring, it became clear that the resulting replacement rates were much lower than anticipated.

\footnotetext{
${ }^{3}$ See Annex 1 for a description of the system under current legislation.

${ }^{4}$ This holds even when benchmarking Chile's replacement rates relative to those in countries with defined contribution pensions systems.

${ }^{5}$ See de la Torre and Rudolph (2018) for a discussion.
} 


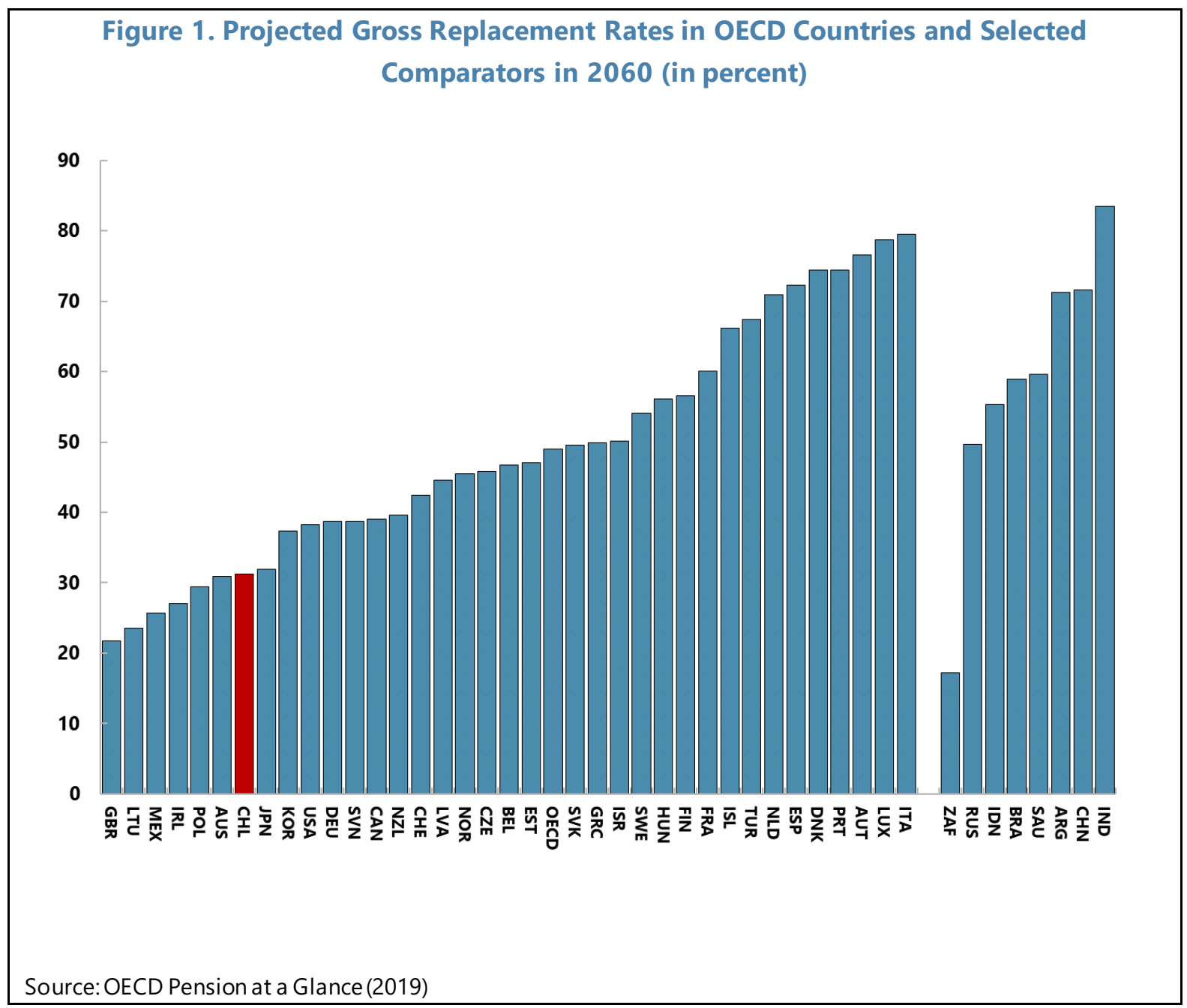

A second factor is the low contribution density. Self-employment and worker turnover have resulted in low contribution densities over workers' careers, especially among women (Figure 2, Panel B). On average, the probability that a male worker contributes to his pension account in a given month is 60 percent, compared to 50 percent for women. ${ }^{6}$ Low propensity to contribute, combined with a lower mandatory retirement age (60 compared to 65 for men), result in lower pensions and replacement rates for women (Figure 3).

${ }^{6}$ The average contribution density for males retiring between 2017 and 2020 was 60 percent and 46 percent for females. 


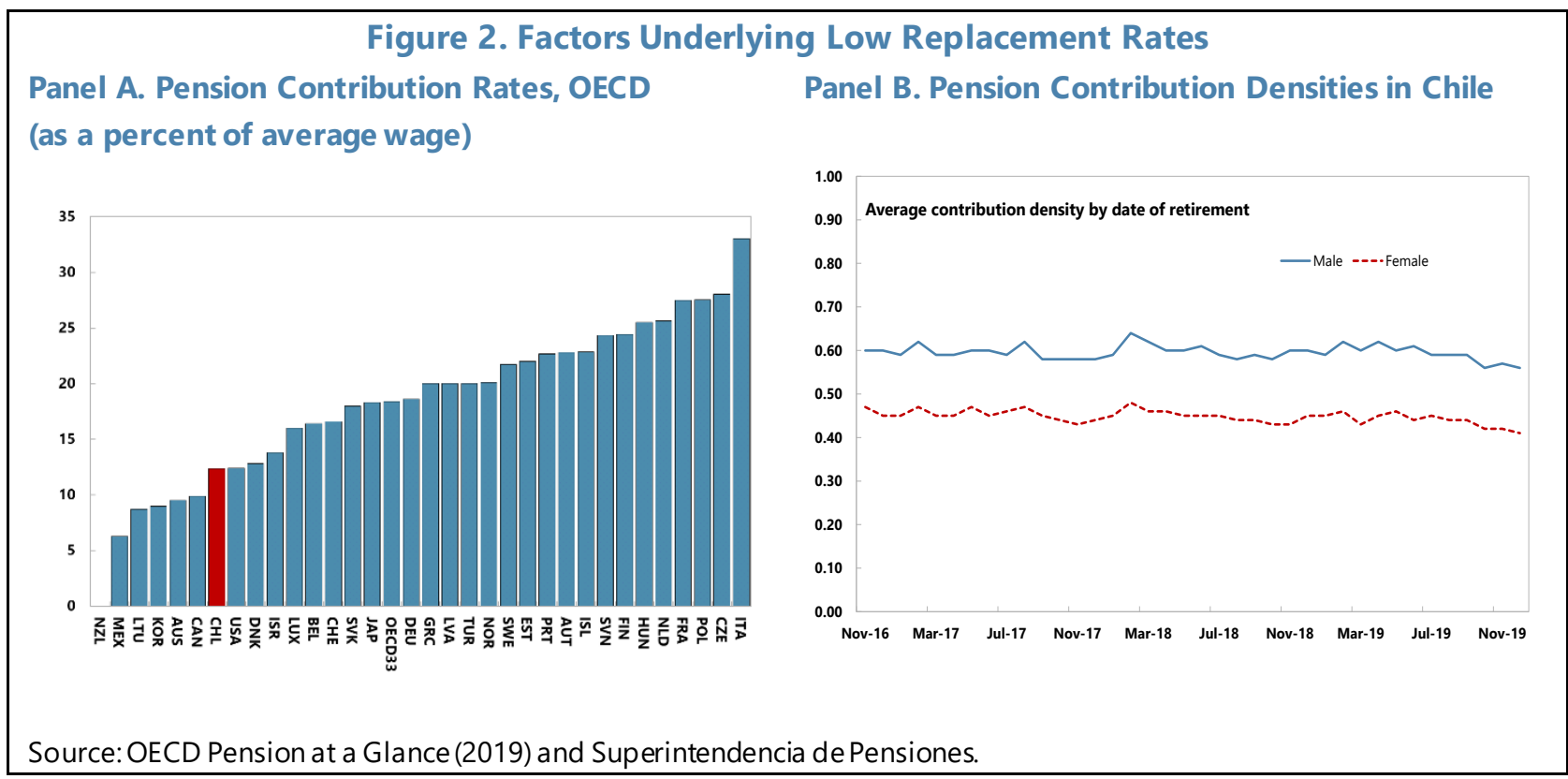

A third factor is demographics. Based on data from the supervisory agency and under the assumption described in Annex 2, male workers who are 60-65 years old today are expected to receive a pension of about 45 percent of their final wage prior to retirement (Figure 3 , Panel A). By contrast, male workers who entered the labor market recently (those who are 20-25 year old in 2020) are expected to have replacement rates of roughly 40 percent. $^{7}$ This reduction in expected replacement rates is in part related to the fact that you nger generations face the prospects of longer life horizons. Compared to those who are 65 today, estimates of increasing life expectancy imply that workers that will retire in 40 years' time will have to spread their savings over an additional five years (four years for women, Figure 3 panel B).

A fourth factor is lower future expected returns on savings. Real interest rates have gradually declined since the adoption of the defined contribution system (Figure 3, panel C), and are expected to remain low over the medium term. This means that today's youngest cohorts will accumulate assets at a lower rate compared to what older cohorts have achieved so far.

\section{Demographic trends and declining global returns also explain differences between expected replacement rates at the time the system was adopted and those observed} when the first cohorts retired. To gauge the impact of these two factors we perform the same exercise as the one underlying Figure 3 panel A, and compute the pension of a hypothetical male worker who entered the labor force in 1981 and calculate his replacement rate at retirement under different assumptions related to life expectancy and returns (we

\footnotetext{
${ }^{7}$ A similar pattern is observed for women - the 60 to 65 age group have average projected replacementrates of roughly 40 percent, while those who are those who a re 20 to 25 years old a re expected to have replacement rates of 30 percent at retirement.
} 
maintain unchanged other assumption for comparability, such as a real wage growth of 1.25 percent). Let us first consider the implicit life expectancy of a retiree in 1981 (which was about 78 years old) and a conservative real return on assets of 6 percent (which is much lower than the average return since then, see Figure 3, panel C). ${ }^{8}$ Under these assumptions, the replacement rate would be about 90 percent (a higher return, such the one prevailing on average over the 1981-2019 period of 8 percent, would deliver even higher replacement rates, reaching 160 percent). In a second exercise we analyze the effect of an increase in life expectancy, which causes pensioners to stretch their pensions further. The increase in life expectancy of a current male retiree from the one expected in 1981 to the one expected in 2020 lowers the replacement rate from 90 percent to 62 percent. Additionally, the fall in global returns has slowed the accumulation of pension account balances and caused replacement rates to fall over time. Keeping life expectancy at its 1981 level but lowering the real return on assets to 4.15 percent causes the replacement rate to fall from 90 percent to 55 percent. Combining the increase in life expectancy with the fall in global safe interest rates lowers the replacement rate further, to 38 percent (Figure 3, panel D), which is the one reported above for the current young male entering the workforce today and contributing the in the current pension system (as in Figure 3, panel A).

\section{The exercise illustrates that at its inception the system was well positioned to deliver adequate pension levels and replacement rates, and even today the system delivers higher replacement rates compared to a hypothetical fiscally neutral PAYG system. ${ }^{9}$} Changes to life expectancy and real interest rates coupled with parameters of the pension system (i.e. contribution rates and the retirement age) that have not adapted to changes have contributed to outcomes ending up being subpar. However, the current system delivers replacement rates that stand above those of a hypothetical PAYG system. To illustrate th is, we compute replacement rates for a PAYG system that is fully financed via contributions of current workers (i.e. there is no additional fiscal support) and that has parameters consistent with those of the current system (similar contribution rates as the current system and similar wage growth and demographic trends as those observed in the data). Such a system would produce replacement rates for a hypothetical male (female) worker retiring today that are 5 (2) percentage points lower compared to those of the current system (Figure 3, panel E).

\footnotetext{
${ }^{8}$ In the absence of exact demographic information as of 1981, the ex ercise uses the information implicit in the CNU (CapitalNecesario Unitario), which is the ca pital that a pensioner needs in order to finance one annual unit of the life annuity pension, and combines the life expectancy of the pensioner and the safe interest ra te at the time of retirement. The CNU for a male retiree in 1981 increased by 46 percent to today, which mostly reflects changes in life expectancy. Notably, the implicit calculation is a lso in line with the OECD figure for 1990 life expectancy (78), so this exercise is not bia sing the calculation of the replacement ra te upwards.

${ }^{9}$ The PAYG system assumes a higher contribution rate to makethe system fiscally sustainable and an interest rate that tracks real wa ge increases.
} 
Figure 3. Replacement Rates in Chile

Panel A. Average Expected Replacement Rates by Cohort and Gender

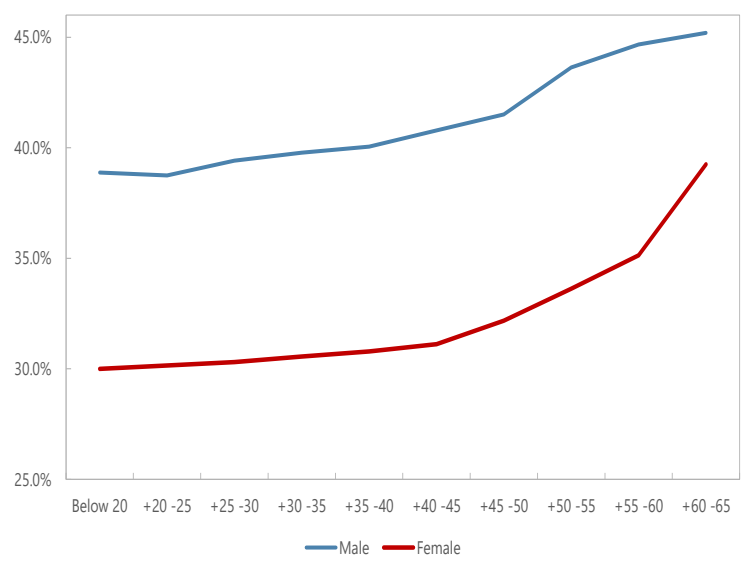

Panel C. Annual Real Returns of Pension

Funds (Fund $C$, in percent)

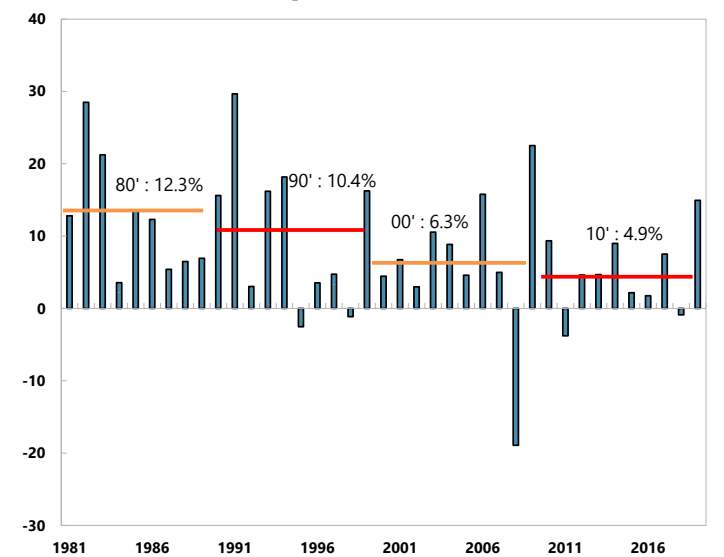

Panel B. Remaining Life Expectancy at 65 in Chile (in years)

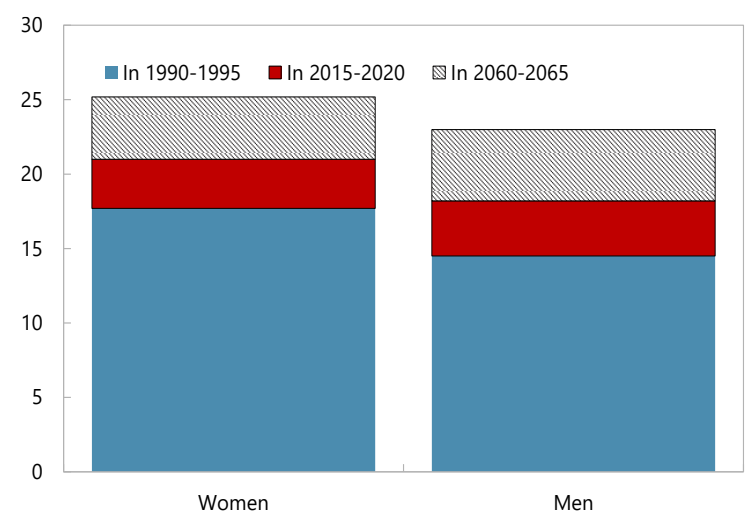

Panel D. Hypothetical Replacement Rates in 2020 (in percent)

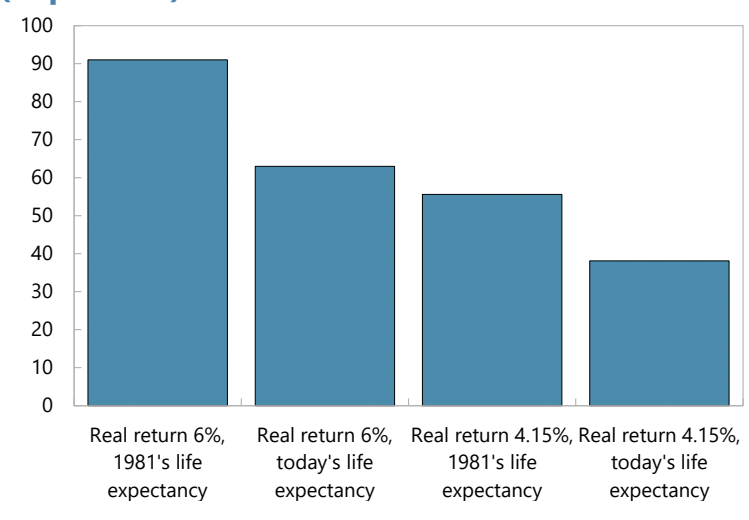

Panel E. Hypothetical Replacement Rate for current system and Pay-As-You-Go system $40 \%$

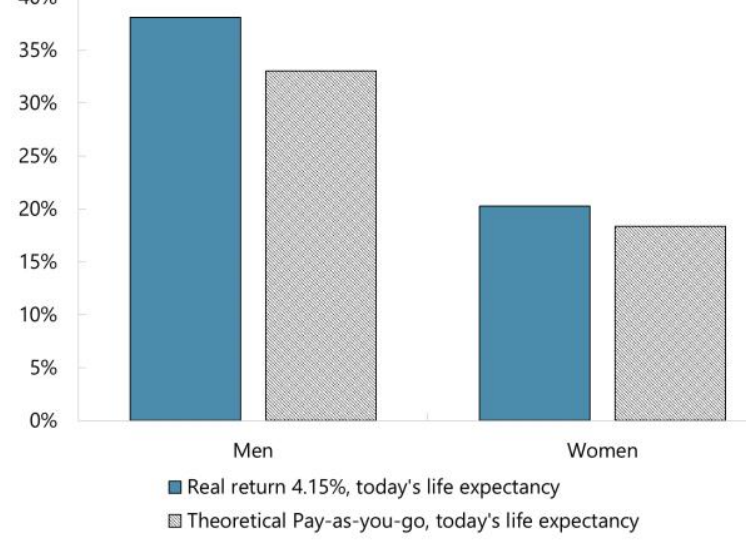

Sources: Authors' calculations based on data from Superintendencia de Pensiones and OECD. 


\section{Beyond averages, there is a large degree of heterogeneity in both projected pension} levels and expected replacement rates within cohorts. A large share of the population of older cohorts is found in the low end of the distribution of projected pensions. Roughly two thirds of the 55-60 cohort (600,000 people) and 50 percent of those 40-45 (approximately 600,000 ) were projected to retire with a pension below $10 \mathrm{UF}$ prior to withdrawals (Figure 4, Panel A). ${ }^{10}$ By contrast, the mode of the distribution of projected pensions of those who are currently young is between 10 and $15 \mathrm{UF}$, but there is also a significant number of people falling in the 5-10 UF category. The distribution of expected replacement rates, on the other hand, presents a bimodal shape for all cohorts, and in each cohort replacement rates range from the low 20s to 100 percent (Figure 4, Panel B). The bimodal shape captures the fact that women, who account for roughly half of the population in each cohort, have lower expected replacement rates than men, and the wide range of expected replacement rates reflects the large difference in expected replacement rates between low and high wage earners.

\section{Figure 4. Distribution of Projected Pensions and Expected Replacement Rates, by Selected} Cohorts

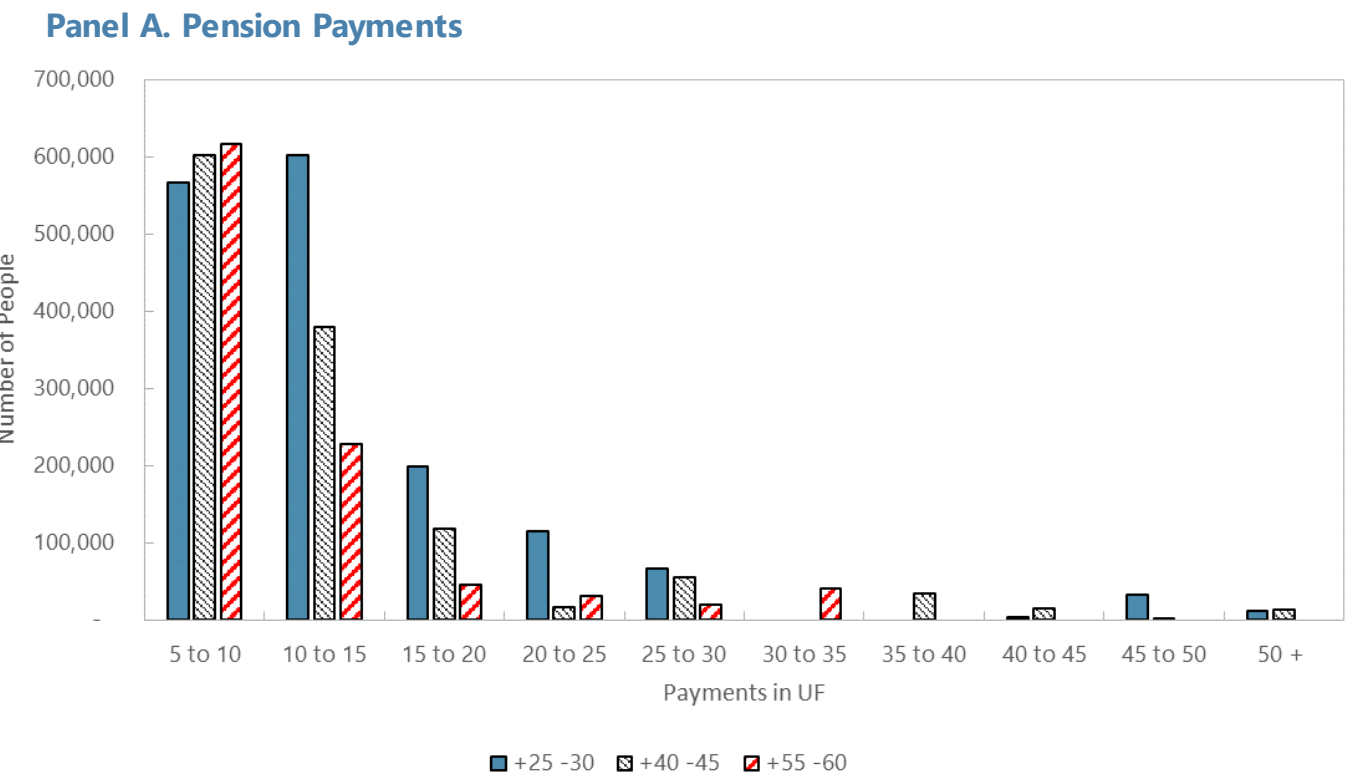

\footnotetext{
${ }^{10}$ Unidades de fomento, UF, is a Unit of account used in Chile. The exchange rate between the UF and the Chilean peso is constantly adjusted for inflation so that the UF value remains almost constant on a daily basis during low inflation. At end-February 2021, 1 UF was equivalent to US $\$ 41$, therefore 10 UF to 15 UF is about US $\$ 410$ to $\$ 620$.
} 
Figure 4. Distribution of Projected Pensions and Expected Replacement Rates, by Selected Cohorts (Concluded)

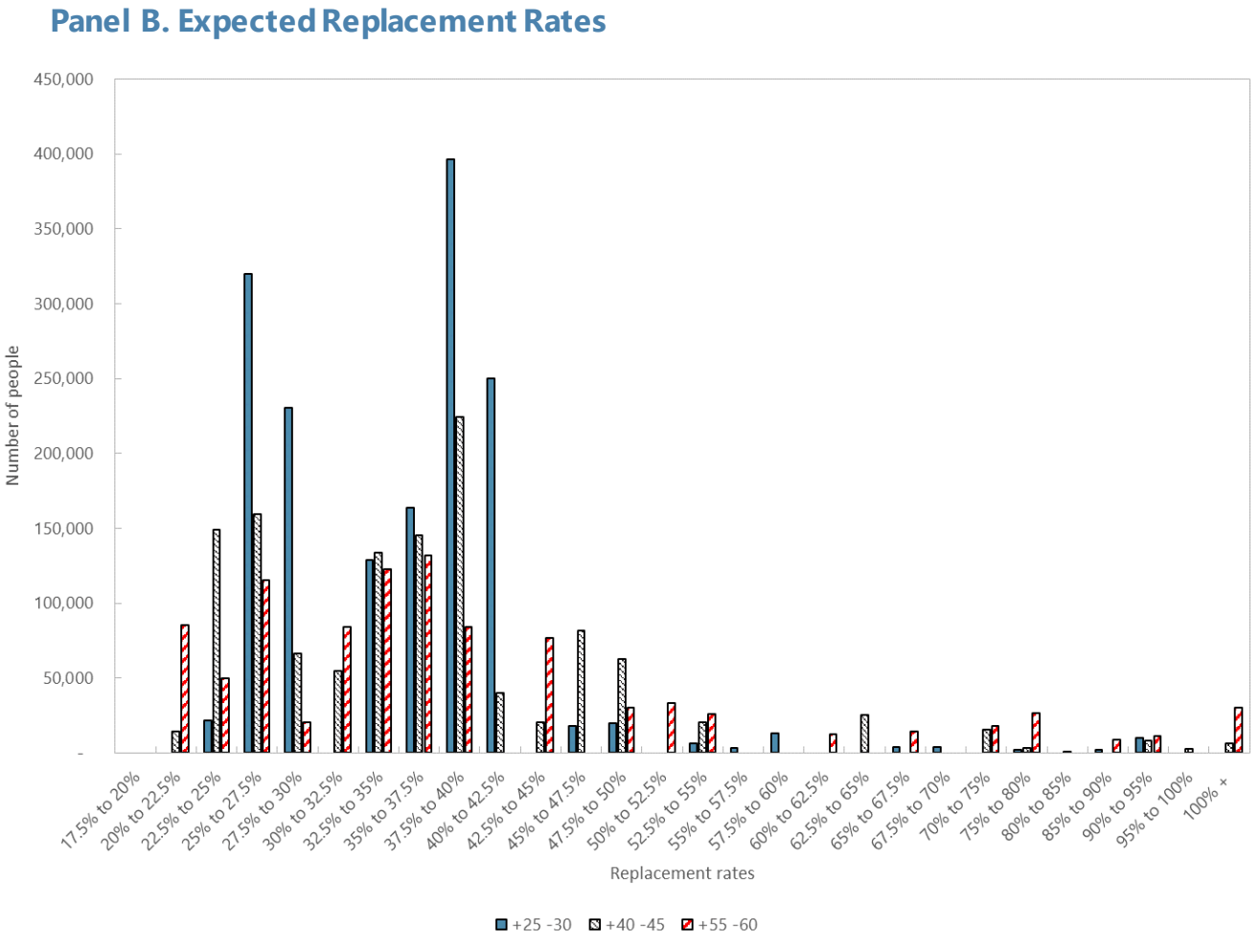

According to projections of outcomes for future retirees, average replacement rates would be significantly lower in absence of the solidarity pillar. In 2008 Chile introduced a solidarity pillar to supplement pensions of individuals with low self-financed pensions, to address poverty among retirees. ${ }^{11}$ Benefits stemming from the solidarity pillar were (before the 2020 pension withdrawals) projected to account for approximately 30 percent of total expected average pension at retirement for men and 50 percent for women prior to withdrawals (Figure 5). ${ }^{12} 13$ In turn, the solidarity pillar increases the expected average replacement rate for those who contributed to the pension system in 2020 by almost 15 percentage points for men, and by close to 20 percentage points for women.

\footnotetext{
${ }^{11}$ See Annex 1 for a description of the differentelements of the solidarity pillar.

${ }^{12}$ See Annex 3 for a detailed exposition of the characteristics of the pensions system across cohorts and a sset ba lances. The averages presented in Figure 5 reflect the fact that for some retirees in the lower 60 percent of the income distribution, the solidarity pillar can represent close to 100 percent of their pension.

${ }^{13}$ This is consistent with Fajnzylber (2019), who argues that the solidarity pillar has provided transparent and targeted subsidy to individual who need it the most and compensates for gender differences.
} 
Figure 5. The Impact of the Solidarity Pillar on Pensions of Future Retirees

Panel A. APS as a share of Total Pensions, by Age Groups and Gender (in percent)



Panel B. Contribution of APS and Self-funded

Pensions to Replacement Rates (in percent)

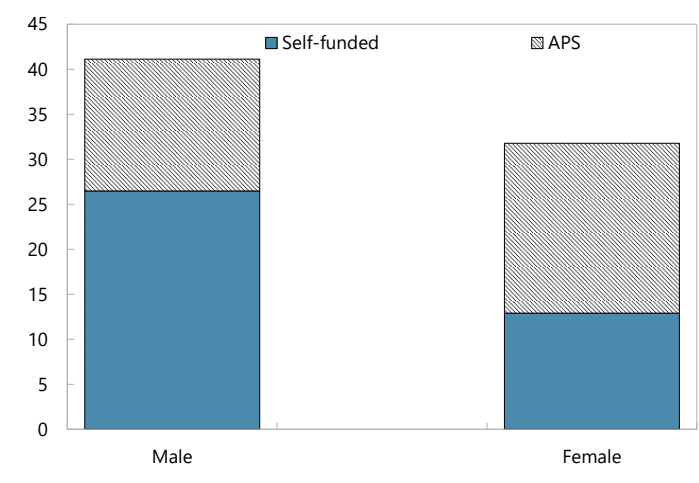

Source: Authors' calculations based on data from the Superintendencia de Pensiones.

The fiscal footprint of the Chilean system is relatively small and expected to decline as total costs converge to those associated with the solidarity pillar. The fiscal cost of the pensions system has been trending downward in Chile, although this mainly reflects the decline in the share of retirees receiving benefits from the old PAYG system. Compared to other countries, many of which have PAYG or hybrid systems, Chile currently devotes a relatively small share of GDP to the civilian pension system. OECD (2019) shows that in 2015 fiscal costs associated with old-age and survivors benefits were smaller in Chile than in other OECD countries, except for Iceland and Mexico (Figure 6, panel A). By 2020, the fiscal costs were approximately 2.2 percent of GDP, of which 1.1 percent stem from the solidarity pillar. Total fiscal costs will converge to the costs of the solidarity pillar, which prior to withdrawals were projected to increase gradually to 1.6 percent of GDP by $2060^{14}$, assuming that the parameters of the solidarity pillar related to a minimum pension to individuals with no self-funded pension (pensión básica solidaria, PBS) and a government supplement to individuals with low self-funded pensions (Aporte previsional solidario, APS) remain unchanged (Figure 6, panel B). However, in an alternative scenario where the parameters of the solidarity pillar, PBS and APS, are assumed to grow at the same rate as wages ( 1.25 percent per year in real terms), then the fiscal costs can be expected to reach 3 percent of GDP in 2060.

\footnotetext{
${ }^{14}$ Fiscal costs reflect the authorities' projections of future costs a ssociated with theold PAYG system up to 2050.
} 
Figure 6. Fiscal Costs Associated with the Pension System-Pre-Withdrawal

Panel A. Cross-Country Comparison of Fiscal Costs—2015

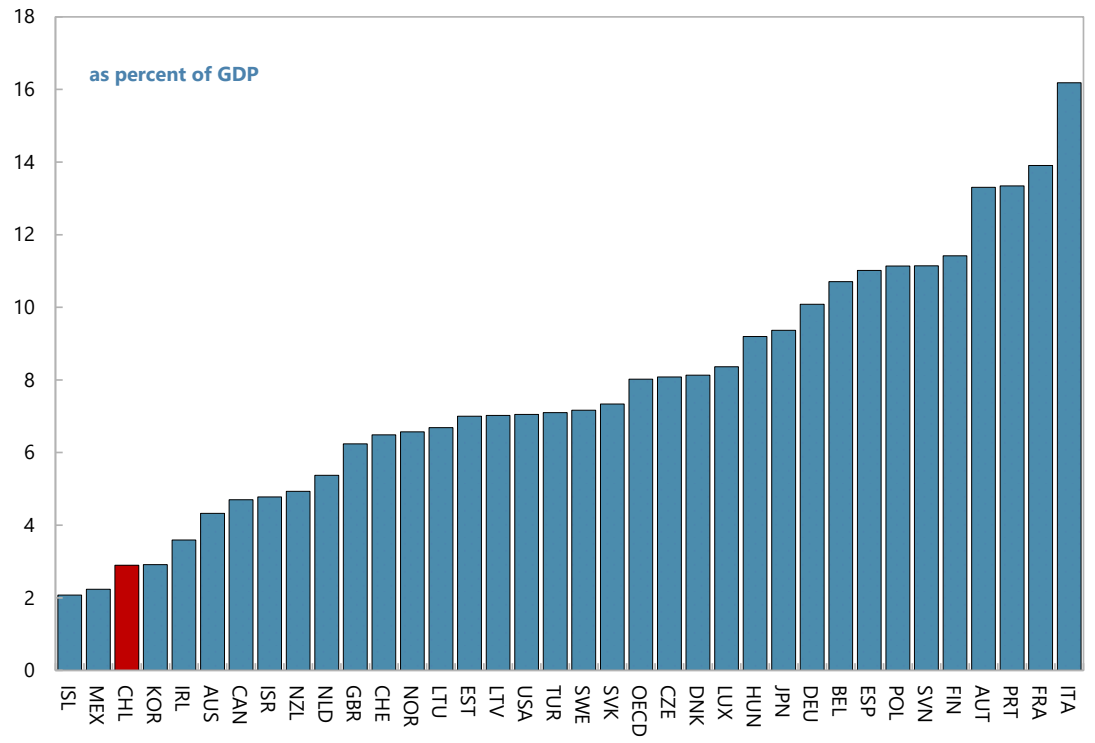

Panel B. Fiscal Costs in Chile, Baseline and Alternative Scenario (\% of GDP)

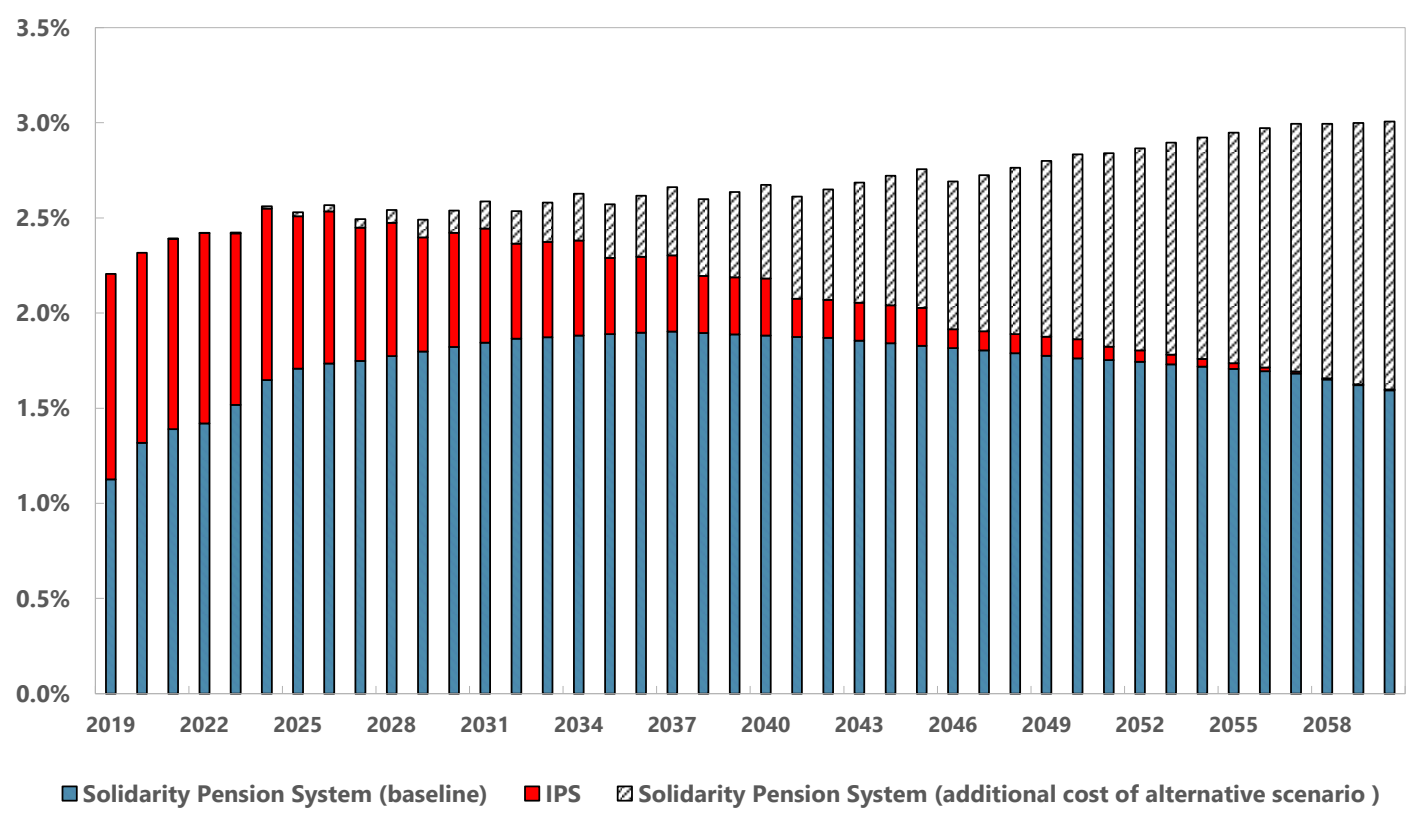

Sources: Authors' calculations based on OECD (2019) and Superintendencia de Pensiones. 


\section{The Pension Systemin the Aftermath OF Withdrawals}

\section{A. A Description of the Withdrawals}

As part of the policy response to mitigate the adverse economic effects of COVID-19, Congress authorized workers to tap into their private pension accounts. Two rounds of withdrawals were approved, in July 2020 and December 2020, and a third was approved in April 2021. As of August 2021, Congress is discussing a fourth round of withdrawals but it is still unclear whether it will be approved and, if so, what would be the exact terms. Total withdrawals reached US $\$ 48$ billion (or about 19 percent of GDP) by early-May 2021. The allowed amount for each withdrawal was generally 10 percent. However, the introduction of minimum and maximum withdrawals, set at 35 UF and 150 UF respectively (Table 1), meant that the share of assets that could be withdrawn varied with balances (Figure 7). ${ }^{15}$ The first and third withdrawals were tax-exempt, while the second was exempt only for those who earned on average below a certain threshold (see Table 1).

Figure 7. Pension Account Balances and Maximum Withdrawal Amount

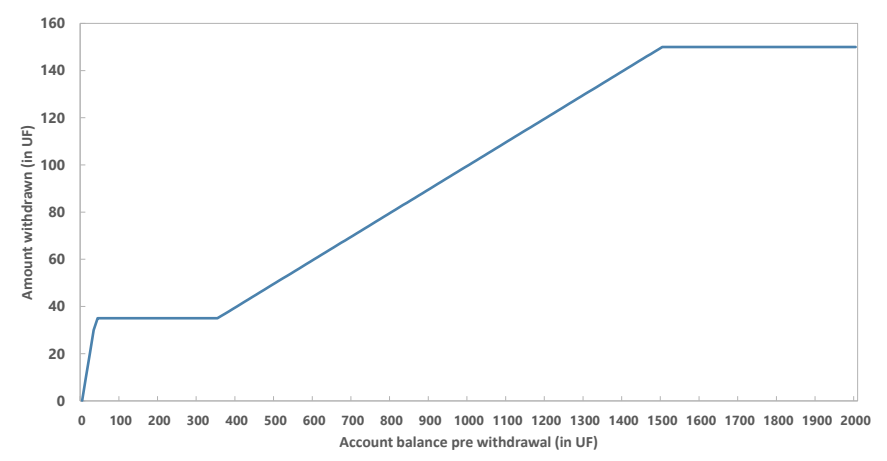

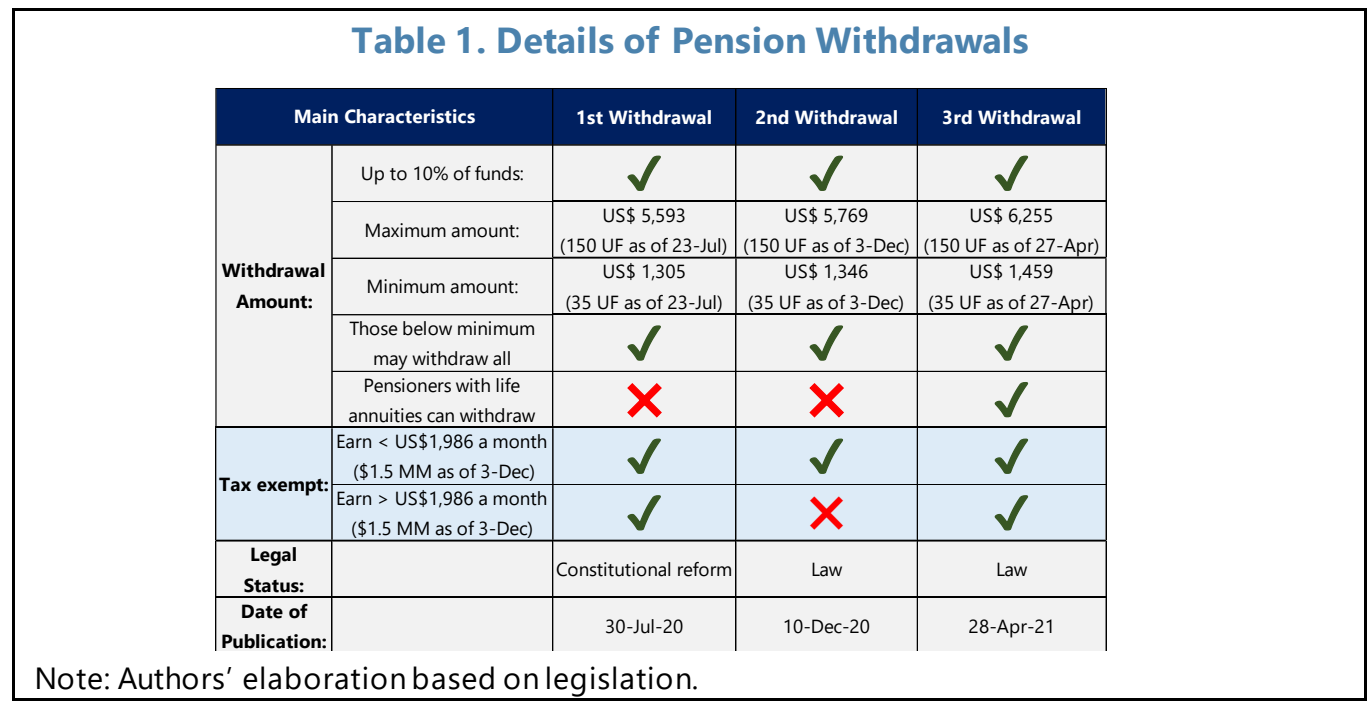

\footnotetext{
${ }^{15}$ The first and third withdrawal wa s tax-exempt, while the second one was exempt only for those who earned on a verage below a certain threshold (see Table 1).
} 


\section{Official data shows that, up to February 2021 , close to 10.5 million people withdrew money using the first or second withdrawals and, of those, 30 percent depleted their} accounts. ${ }^{16}$ Roughly 95 percent of all people with positive pension balances in June 2020 made use of at least one of the first two withdrawals, and over 7 million people withdrew twice (almost two thirds of people with positive balances). The average amount withdrawn in each round was about US $\$ 2,000$ and the average individual took 40 percent of their account balance in the first withdrawal and slightly over 30 percent in the second withdrawal (Table 2). This reflects the fact that a large share of people in the system had balances below the 35 UF threshold, and close to 3 million people depleted their account balance from the first two withdrawals, with close to 3.8 million people exhausting their accounts through the 3 withdrawals. Furthermore, the distribution of pensions accounts saw a leftward shift following the withdrawals, with a significant reduction in the number of people with intermediate balances and a large increase in individuals with low balances (Figure 8).

\footnotetext{
${ }^{16}$ Close to 3 million people depleted their a ccounts up to February using the first two withdrawals. Including the $3{ }^{\text {rd }}$ withdra wal, close to 3.8 million have depleted their a ccounts.
} 
Table 2. Distribution of Withdrawals by Initial Balance

Panel A. Amount Withdrawn in the First Pension Withdrawal, by Account Balance (As of April 30, 2021, in US\$)

\begin{tabular}{l|c|c|c|cc}
\hline \multicolumn{2}{|c|}{ Balance and allowed withdrawal } & $\begin{array}{c}\text { Amount } \\
\text { withdrawn }\end{array}$ & $\begin{array}{c}\text { Amount } \\
\text { withdrawn } \\
\text { of balance) }\end{array}$ & \multicolumn{2}{c}{ People } \\
\hline $\begin{array}{l}\text { Balance in AFP } \\
\text { (US\$ as of July 23) }\end{array}$ & Allowed withdrawal & Mean & Mean & Number \\
\hline Less than $\$ 1,305$ & $100 \%$ of balance & $\$ 524$ & $100 \%$ & $2,234,467$ & $20.5 \%$ \\
Between $\$ 1,305-\$ 13,050$ & $\$ 1,305:>10 \%$ of balance & $\$ 1,307$ & $35.6 \%$ & $4,490,924$ & $42.9 \%$ \\
Between $\$ 13,050-\$ 55,928$ & $10 \%$ of balance & $\$ 2,722$ & $10.0 \%$ & $3,126,391$ & $29.6 \%$ \\
More than $\$ 55,928$ & $\$ 5,593:<10 \%$ of balance & $\$ 5,550$ & $6.2 \%$ & 699,205 & $6.5 \%$ \\
No information & - & - & - & 69,128 & $0.5 \%$ \\
Total & & $\$ 1,843$ & $39.7 \%$ & $10,620,115$ & $100 \%$ \\
\hline
\end{tabular}

Panel B. Amount Withdrawn in the Second Pension Withdrawal, by Account Balance (As of April 23, 2021, in US\$)

\begin{tabular}{|c|c|c|c|c|c|}
\hline \multicolumn{2}{|c|}{ Balance and allowed withdrawal } & \multirow{2}{*}{$\begin{array}{c}\begin{array}{c}\text { Amount } \\
\text { withdrawn }\end{array} \\
\text { Mean }\end{array}$} & \multirow{2}{*}{$\begin{array}{c}\begin{array}{c}\text { Amount } \\
\text { withdrawn } \\
\text { (\% of balance) }\end{array} \\
\text { Mean }\end{array}$} & \multicolumn{2}{|c|}{ People } \\
\hline $\begin{array}{l}\text { Balance in AFP } \\
\text { (US\$ as of December 3) }\end{array}$ & Allowed withdrawal & & & Number & $\%$ \\
\hline Less than $\$ 1,346$ & $100 \%$ of balance & $\$ 558$ & $100 \%$ & $1,190,895$ & $15.1 \%$ \\
\hline Between $\$ 1,346-\$ 13,461$ & $\$ 1,346:>10 \%$ of balance & $\$ 1,340$ & $33.6 \%$ & $3,478,818$ & $44.0 \%$ \\
\hline Between $\$ 13,461-\$ 57,690$ & $10 \%$ of balance & $\$ 2,719$ & $10.0 \%$ & $2,716,939$ & $34.3 \%$ \\
\hline More than $\$ 57,690$ & $\$ 5,769:<10 \%$ of balance & $\$ 5,730$ & $6.3 \%$ & 461,056 & $5.8 \%$ \\
\hline No information & - & - & - & 62,653 & $0.8 \%$ \\
\hline Total & - & $\$ 1,960$ & $33.9 \%$ & $7,910,361$ & $100.0 \%$ \\
\hline
\end{tabular}

Panel C. Amount Withdrawn in the Third Pension Withdrawal, by Account Balance

(As of May 14, 2021, in US\$)

\begin{tabular}{|c|c|c|c|c|c|}
\hline \multicolumn{2}{|c|}{ Balance and allowed withdrawal } & \multirow{2}{*}{$\begin{array}{c}\text { Amount } \\
\text { withdrawn }\end{array}$} & \multirow{2}{*}{\begin{tabular}{|c|}
$\begin{array}{c}\text { Amount } \\
\text { withdrawn } \\
\text { (\% of balance) }\end{array}$ \\
Mean
\end{tabular}} & \multicolumn{2}{|c|}{ People } \\
\hline $\begin{array}{l}\text { Balance in AFP } \\
\text { (US\$ as of April 27, 2021) }\end{array}$ & Allowed withdrawal & & & Number & $\%$ \\
\hline Less than $\$ 1,459$ & $100 \%$ of balance & $\$ 606$ & $100 \%$ & 806,055 & $14.3 \%$ \\
\hline Between $\$ 1,459-\$ 14,594$ & $\$ 1,459:>10 \%$ of balance & $\$ 1,461$ & $32.1 \%$ & $2,530,247$ & $45.0 \%$ \\
\hline Between $\$ 14,594$ - $\$ 62,547$ & $10 \%$ of balance & $\$ 2,822$ & $10.0 \%$ & $1,980,438$ & $35.2 \%$ \\
\hline More than $\$ 62,547$ & $\$ 6,255:<10 \%$ of balance & $\$ 6,226$ & $6.3 \%$ & 275,292 & $4.9 \%$ \\
\hline No information & - & - & - & 32,117 & $0.6 \%$ \\
\hline Total & - & $\$ 2,057$ & $32.8 \%$ & $5,624,149$ & $100 \%$ \\
\hline
\end{tabular}

Source: Superintendencia de Pensiones. Note: Data on withdrawals are converted from UFs to US $\$$ using the exchange rate at the time of the announcements. For the first withd rawal this was July 23,2020 , for the second withdrawal it was December 3, 2020, and for the third withdrawal it was April 27, 2021. 


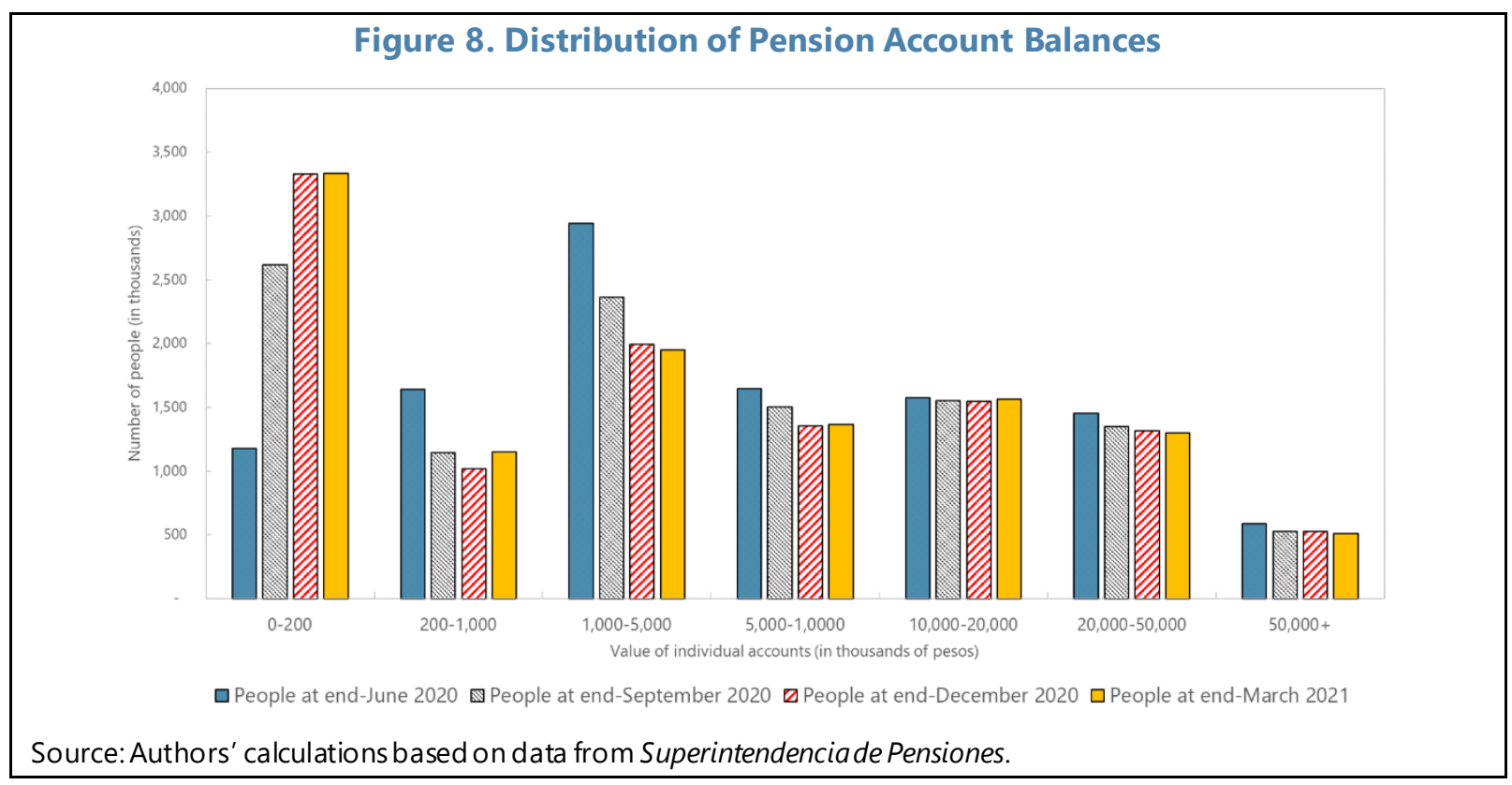

The median person who withdrew was in the 36-45 year-old range; younger people withdrew smaller amounts but a larger share of their pension balances. Since most people made at least one withdrawal, the median age of those who withdrew funds from the three withdrawals tracked the median age of the overall system, which is approximately 40 years. Importantly, account balances are increasing in age, which has two implications. First, younger cohorts could take out a larger share of their balances. Data from SP shows that, on average, individuals 25 and younger took close to 90 percent of their balance in each withdrawal, while individuals in the 55-65 year-old group withdrew an average 20 to 25 percent of their balance each time (Table 3). The median group, those in the 35-45 age bracket, withdrew close to 30 percent of their balance in each round. A second implication is that, even though most of the people that withdrew were young, the share of total assets withdrawn by older individuals is larger (as they hold a larger share of the system's assets). Of the 48 billion dollars withdrawn in the two rounds, about 55 percent came from individuals 46 and older. 
Table 3. Distribution of Withdrawals by Age

Panel A. Amount Withdrawn in the First Pension Withdrawal, by Age

(As of April 30, 2021, in US\$)

\begin{tabular}{l|r|c|c|c}
\cline { 2 - 5 } & \multicolumn{2}{|c|}{ People } & Amount requested & Share of balance requested \\
\hline Age bracket & \multicolumn{1}{c|}{ Number } & \multicolumn{1}{c|}{$\%$} & Average (US\$ as of Jul 23) & Mean \\
\hline Below 25 & $1,102,550$ & $10.4 \%$ & $\$ 675$ & $88.1 \%$ \\
$26-35$ & $2,873,811$ & $27.1 \%$ & $\$ 1,216$ & $48.8 \%$ \\
$36-45$ & $2,412,747$ & $22.7 \%$ & $\$ 1,863$ & $31.0 \%$ \\
$46-55$ & $2,229,042$ & $21.0 \%$ & $\$ 2,478$ & $25.9 \%$ \\
$56-65$ & $1,595,726$ & $15.0 \%$ & $\$ 2,770$ & $24.7 \%$ \\
$66+$ & 398,611 & $3.8 \%$ & $\$ 2,234$ & $30.6 \%$ \\
No information & 7,628 & $0.1 \%$ & - & - \\
Total & $10,620,115$ & $100 \%$ & $\$ 1,843$ & $39.7 \%$ \\
\hline
\end{tabular}

Panel B. Amount Withdrawn in the Second Pension Withdrawal, by Age

(As of April 23, 2021, in US\$)

\begin{tabular}{l|r|r|c|c}
\hline \multicolumn{1}{c|}{} & \multicolumn{2}{|c|}{ People } & Amount requested & Share of balance requested \\
\hline Age bracket & \multicolumn{1}{c|}{ Number } & $\%$ & Average (US\$ as of Dec 3) & Mean \\
\hline Below 25 & 499,898 & $6.3 \%$ & $\$ 693$ & $86.7 \%$ \\
$26-35$ & $2,110,026$ & $26.7 \%$ & $\$ 1,273$ & $45.1 \%$ \\
$36-45$ & $1,938,890$ & $24.5 \%$ & $\$ 1,877$ & $28.3 \%$ \\
$46-55$ & $1,826,042$ & $23.1 \%$ & $\$ 2,516$ & $23.0 \%$ \\
$56-65$ & $1,259,537$ & $15.9 \%$ & $\$ 2,855$ & $20.8 \%$ \\
$66+$ & 274,299 & $3.5 \%$ & $\$ 2,316$ & $25.4 \%$ \\
No information & 1,669 & $0.0 \%$ & - & - \\
Total & $7,910,361$ & $100 \%$ & $\$ 1,960$ & $33.9 \%$ \\
\hline
\end{tabular}

Panel C. Amount Withdrawn in the Third Pension Withdrawal, by Age (As of May 14, 2021, in US\$)

\begin{tabular}{l|r|r|c|c}
\cline { 2 - 5 } & \multicolumn{2}{|c|}{ People } & Amount requested & Share of balance requested \\
\hline Age bracket & \multicolumn{1}{c|}{ Number } & \multicolumn{1}{c|}{$\%$} & Average (US\$ as of April 27) & Mean \\
\hline Below 25 & 260,346 & $4.6 \%$ & $\$ 649$ & $88.4 \%$ \\
$26-35$ & $1,452,607$ & $25.8 \%$ & $\$ 1,369$ & $44.6 \%$ \\
$36-45$ & $1,439,173$ & $25.6 \%$ & $\$ 1,935$ & $28.4 \%$ \\
$46-55$ & $1,375,072$ & $24.4 \%$ & $\$ 2,572$ & $23.3 \%$ \\
$56-65$ & 915,760 & $16.3 \%$ & $\$ 2,913$ & $21.1 \%$ \\
$66+$ & 180,574 & $3.2 \%$ & $\$ 2,330$ & $25.2 \%$ \\
No information & 617 & $0.0 \%$ & - & - \\
Total & $5,624,149$ & $100 \%$ & $\$ 2,057$ & $32.8 \%$ \\
\hline
\end{tabular}




\section{B. Assessing the Impact of Withdrawals}

This paper focuses on the effect of withdrawals on pensions, expected replacement rates, and fiscal costs associated with the pension system. The short-term impact of withdrawals has been recently studied in Central Bank of Chile (2020) and Barrero et al. (2020). Pension fund withdrawals mitigated falling household income (Barrero et al. 2020). In turn, withdrawals were associated with a boost in retail sales and consumption of durables (Central Bank of Chile, 2020). However, Barrero et al. (2020) also show that the measure was not well targeted (especially the second withdrawal) as it reached the upper quintiles of the income distribution, who actually saw labor income gains in the first nine months of the pandemic (Figure 9, panel A). ${ }^{17}$ The impact of the third withdrawal is similar, as transfers and withdrawals more than offset any income losses due to the prolonged pandemic into the first half of 2021 (Figure 9, panel B). Moreover, many people seem to have simply transferred the money into their bank account rather than supporting their spending (Figure 9, Panel C).

On the long-term, withdrawals are projected to have an adverse effect on future pensions, and the individual effects will depend on various factors. ${ }^{18}$ Several factors affect the impact of withdrawals on pensions at retirements. First, other things equal, larger withdrawals result in larger reductions in pensions, because of their impact in the balance of pensions accounts. Second, the longer an individual has to rebuild assets, the smaller the impact of withdrawals on pensions. Third, individuals with low wages withdrew proportionally more and hence will not be able to replenish balances as quickly as those with higher wages. Fourth, the expected level of self-funded pensions prior to withdrawals will be important in determining the impact of withdrawals - individuals for whom self-funded pensions were a relatively small component of total pensions (as they were already relying more on the public solidarity contribution) are expected to see a smaller decrease in pensions. Finally, post-withdrawal balances will affect the extent to which an individual becomes eligible for the APS supplement and the value she will receive.

Additionally, withdrawals have implications for the macroeconomy, putting pressure on prices, and on the financial markets, generating greater exchange rate volatility. Pension withdrawals have proved to be a funding source for households across the income distribution (Figure 9), bolstering their consumption during the COVID-19 pandemic. However, stimulus can lead to inflationary pressure, especially during periods of ec onomic recovery and elevated fiscal spending. Withdrawing savings from the AFPs has led to a deterioration of local financial conditions and decoupling of long-term interest rates, as

\footnotetext{
${ }^{17}$ See the Selected Issues Paper that a ccompanied the IMF Country Report No. 21/084 for effect of support mea sures on household income by quintile in a nnual percent change over 2020.

${ }^{18}$ For an analysis of the short-term impact of withdrawals see Central Bank of Chile (2020) and Barrero et a 1. (2020).
} 
shown in the presentation at the Constitution, Legislation, Justice and Regulation Committee of the Chamber of Deputies presentation in mid-August 2021 by the Central Bank of Chile.

Figure 9. Short-term Impact of Withdrawals

Panel A. Effect of Support Measures on Household Income by Quintile, 2020 (In billions of dollars)

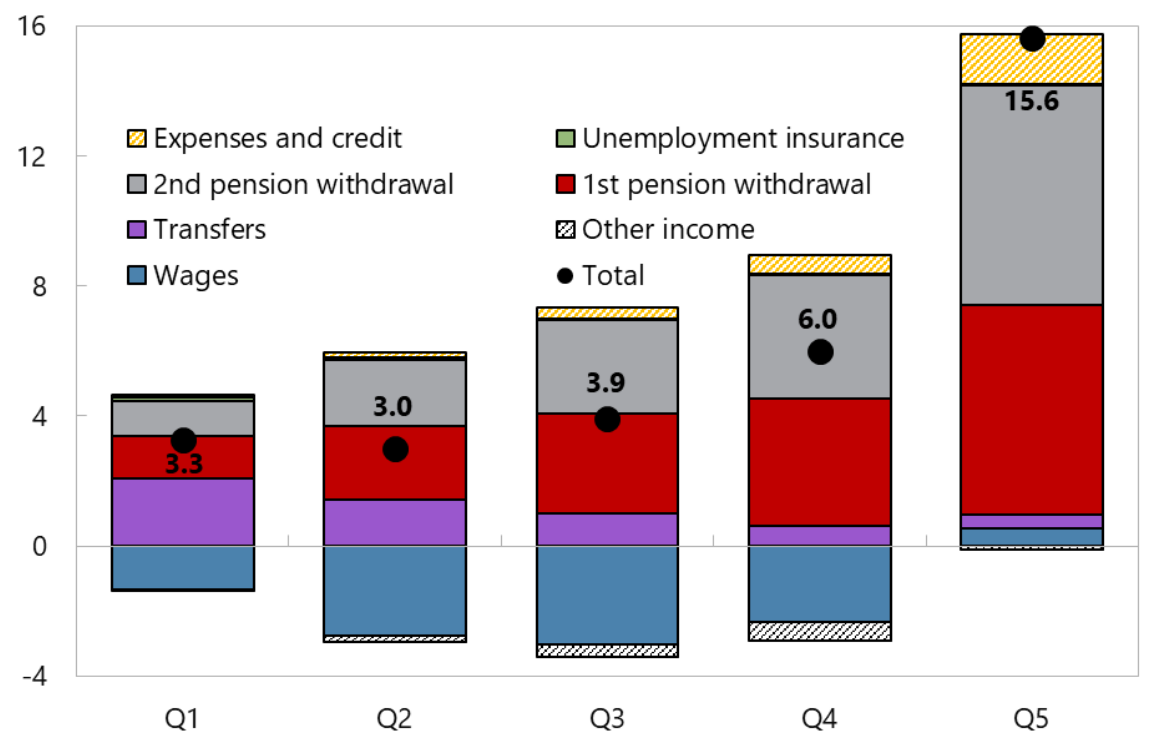

Source: Barrero et al. 2020 and Ministry of Finance.

Panel B. Effect of Support Measures on Household Income by Quintile, 2021H1 (In billions of dollars)

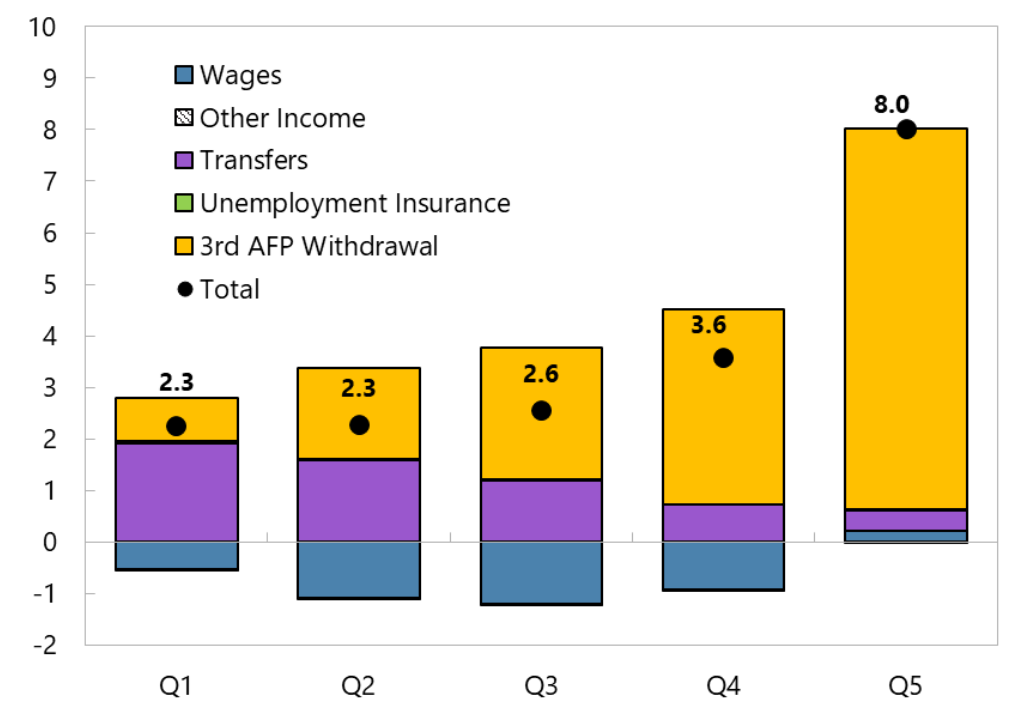

Source: Barrero et al. 2020 and Ministry of Finance. 


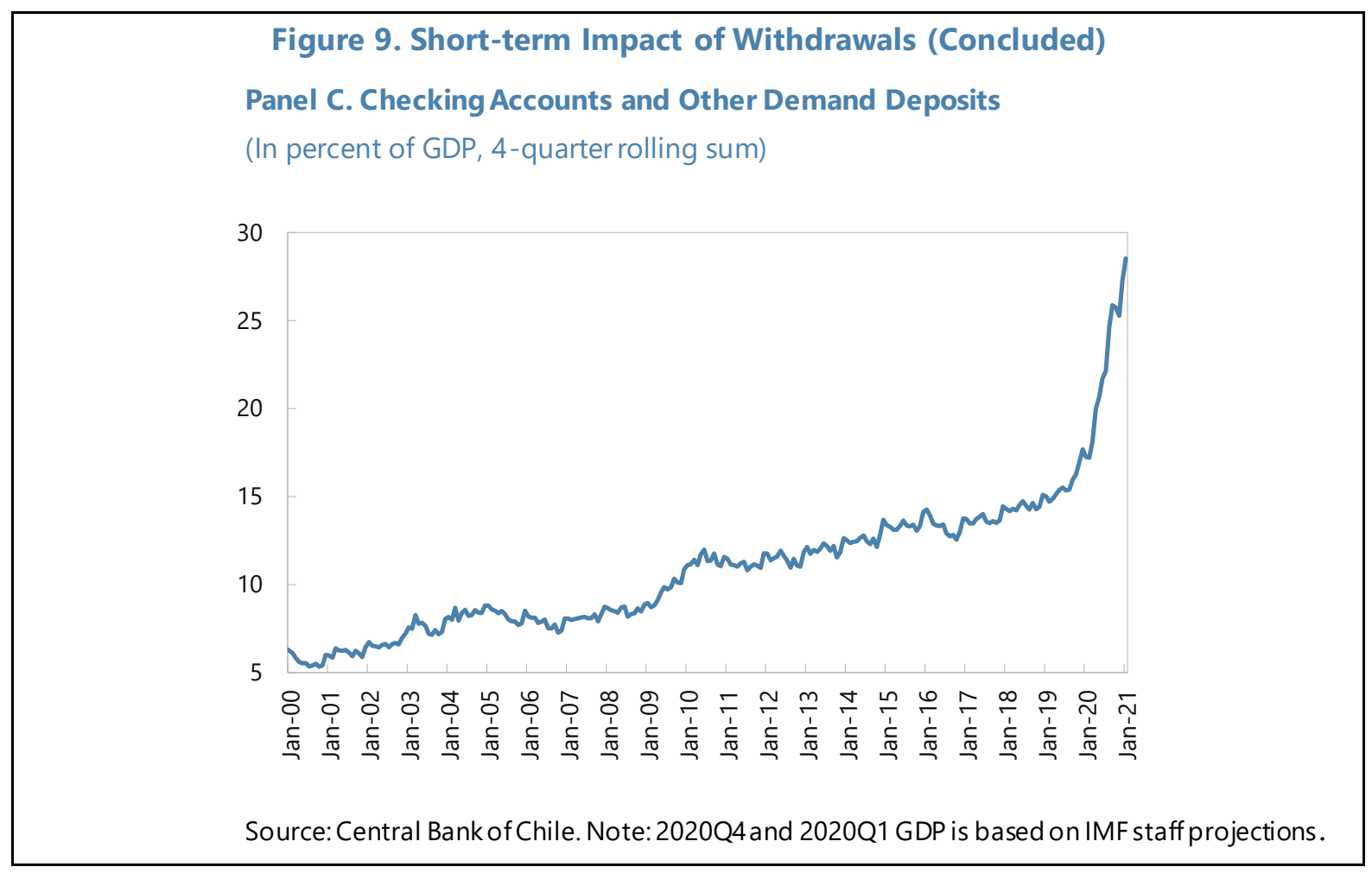

The self-funded portion of pensions is projected to decline on average by 19 percent for men and by almost 23 percent for women, with larger effects among older cohorts

(Figure 10). The self-funded pension is the part that excludes government solidarity support. Males in their 20s are projected to experience average reductions in self-funded pensions of 5 to 12 percent after withdrawals. ${ }^{19}$ By contrast, older cohorts experience reductions that can go up to over 60 percent, with higher numbers for elderly with lower balances that withdrew proportionally more. Women exhibit a similar pattern, but the reductions tend to be larger. This is due to lower wages and contribution densities, and a lower mandatory retirement age. The reduction in self-funded pensions are smaller when we weight by assets. This is due to the fact that, by design, the share of individual assets that were withdrawn declined with the individual pension account balance and that a large share of the population has low pension balances.

\footnotetext{
${ }^{19}$ Lorca (2020) also studies the impact of withdrawals on pensions. However, thea uthor focuses exclusively on the first round of withdrawals.
} 
Figure 10. Reduction in Projected Self-Funded Pensions After Withdrawals, by Gender and Age

Panel A. Male (in percent)

Panel B. Female (in percent)
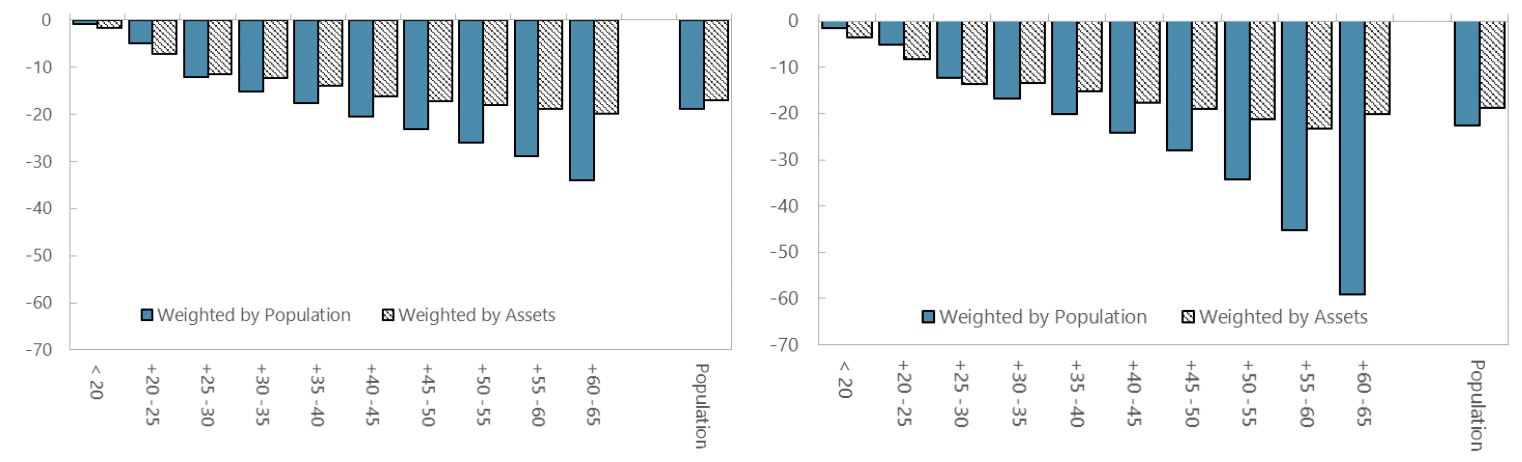

Source: Authors' calculations based on data from Superintendencia de Pensiones.

The projected reductions in self-funded pensions are expected to increase public costs associated with benefits of the solidarity pillar, which would automatically buffer the impact of withdrawals on pensions and expected replacement rates. Replacement rates are projected to decline by about 3 percentage points after withdrawals for the average male worker, and by 1.5 percentage points for female workers (Figure 11, panel A). The smaller impact on women's expected replacement rates is due to the fact that, on average, PBS and APS accounts for a large share of their pension, which makes pensions less sensitive to self-funded account balances. The adverse impact of withdrawals on expected replacement rates is partly mitigated by the increase in government supp ort due to the decline in self-funded pensions. The projection exercise shows that, in absence of additional government support, replacement rates would fall by over 4 percentage points for men and by over 2 percentage points for women. For men, the mitigating effect of government support is largest for the 50-55 age group-APS dampens the adverse effect of withdrawals on expected replacement rate by 1.5 percentage points (Figure 11, Panel B). For women, the additional impact of APS is largest for the 40-45 age group (Figure 11, Panel C). 
Figure 11. Change in Expected Replacement Rates due to Withdrawals

Panel A. Expected Replacement Rates in total Population, by Gender

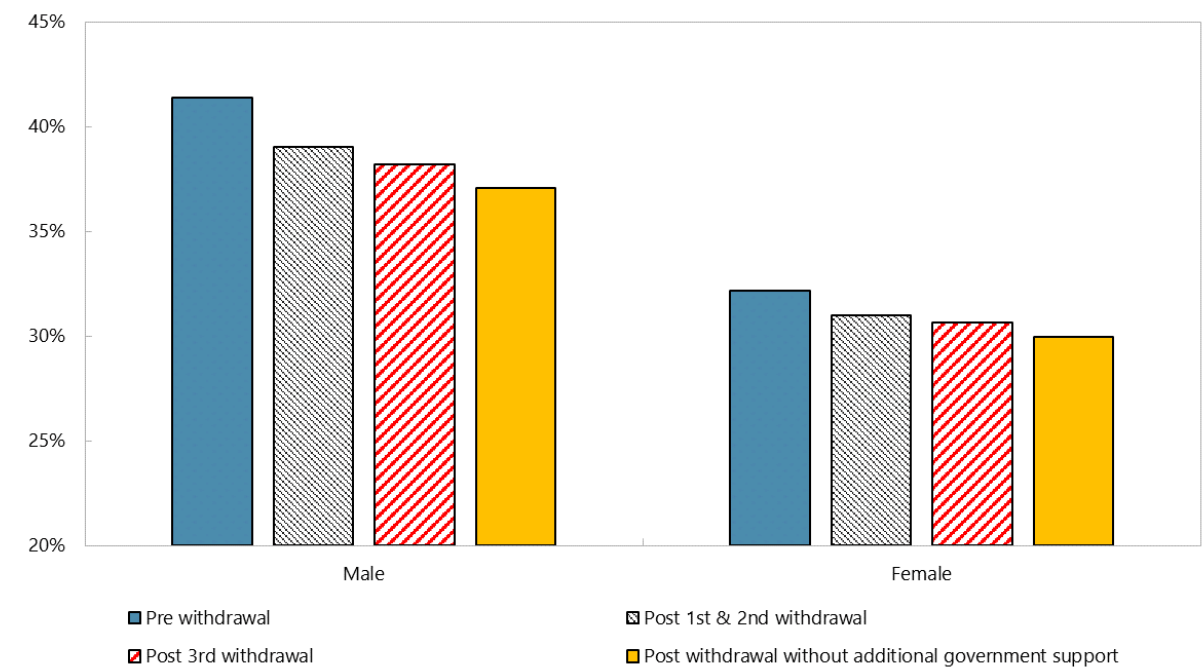

Panel B. Effect by Cohort, Male (in percent)

Panel C. Effect by Cohort, Female (in percent)

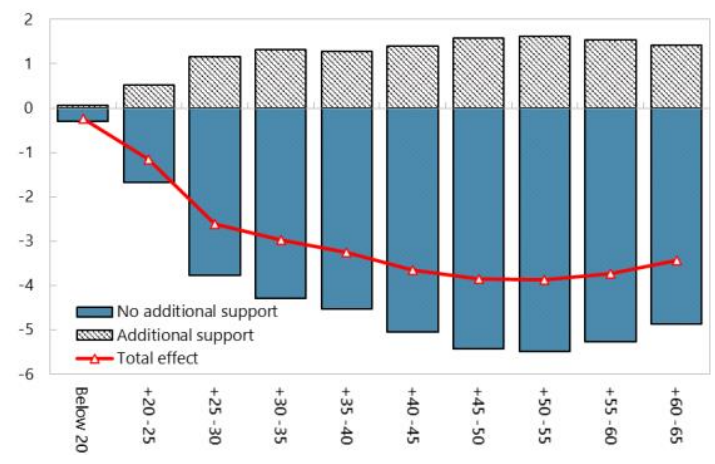

Panel D. Expected Replacement Rates, Pre and Post Withdrawals, Men


Panel E. Expected Replacement Rates, Pre and Post Withdrawals, Women

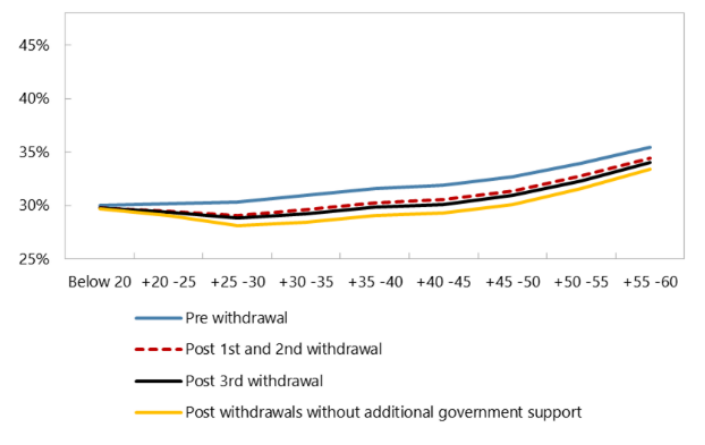

Source: Authors' calculations based on data from Superintendencia de Pensiones. 
The increase in the number of people receiving government supplements (PBS and APS) and in the average amount received are expected to increase fiscal costs over time. ${ }^{20}$ Under the baseline scenario, close to 270,000 additional people are projected to receive self-funded pensions below PMAS at retirement, making them eligible to APS after the withdrawals if they fall into the lower 60 percent of the income distribution $\left(240,000\right.$ under the alternative scenario, Figure 12) ${ }^{21}$. In addition, current recipients are expected to see an increase in APS due to the adverse effect of withdrawals on the self-funded portion of pensions. This leads to an expected increase of 13 percent in the average supplement received by males and a 7 percent increase for females (10 and 5 percent, respectively, in the alternative scenario). The sum of these effects leads to a gradual increase in the fiscal costs, as new cohorts with lower pension account balances retire and get access to additional APS payments. Additional fiscal costs stemming from the solidarity pillar peak around 2060 (Figure 12 panel C), with additional payments of close to 0.17 percent of GDP, $(0.21$ percent in the alternative scenario $)$. The net present value of the additional fiscal costs stands at about 6 percent of 2020 GDP. Notice that these fiscal costs represent an upper bound on the actual costs of withdrawals as some of the individuals that fall below the PMAS line will not fall into the lower 60 percent of the income distribution, and thus will not be eligible to receive benefits stemming from the solidarity pillar. For example, if we assume that withdrawals do not affect the income distribution, such that beneficiaries of the solidarity pillar remain unchanged after withdrawals, fiscal cost would peak at about 0.09 percent of GDP under the baseline, and would amount to a net present value of 3 percent of GDP in 2020. The fiscal cost derived from withdrawals by current pensioners is expected to peak at 0.045 percent of 2020 GDP in the next few years, or if we assume that government support is only provided to pensioners in the lower 60 percent of the income distribution this cost would be 0.025 percent of 2020 GDP. ${ }^{22}$

\footnotetext{
${ }^{20}$ When assessing the fiscal impact of withdrawals, we only ca lculate the cost of the new beneficiaries. In rea lity some of those who are current pensioners could withdraw (those with programmed withdrawals could), but we do not have the balance pensioners with programmed withdrawals.

${ }^{21}$ In the alternative scenario the number of additional people is lower than in the b aseline scenario because in the former the higher PMAS results in a la rger number people receiving a government supplementprewithdra wal, making the change post-withdrawal smaller. A higher PBS, however, implies that the postwithdra wal a mount received by beneficiaries (people who cross the PMAS threshold post-withdrawal a s well those who received a supplement pre-withdrawal) is la rger. The overall effect is a slight increa se in fiscal cost rela tive to the baseline scenario, as visible in Figure 12 panelC and panelD.

${ }^{22}$ Pensioners with life a nnuities were excluded from the $1^{\text {st }}$ and $2^{\text {nd }}$ pension withdrawals while pensioners with programmed withdrawals were allowed to a ccess all three withdrawals.
} 
Figure 12. Fiscal Impact of Withdrawals

Panel A. People with Self-Funded Pensions Between and Above PBS and PMAS

(Baseline, in Thousands)

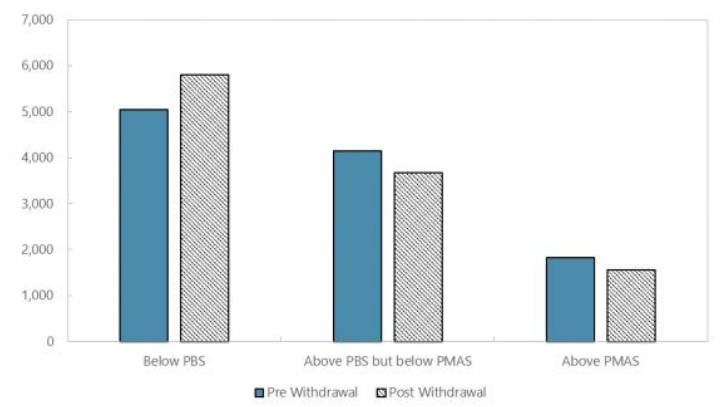

Panel C. Additional APS Costs from Withdrawals from current affiliates, Baseline and Alternative (\% of GDP)

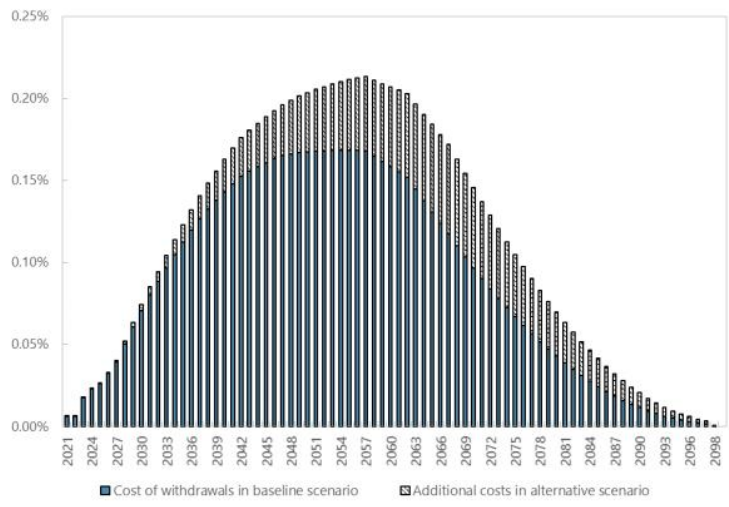

Panel B. People with Self-Funded Pensions Between and Above PBS and PMAS (Alternative, in Thousands)

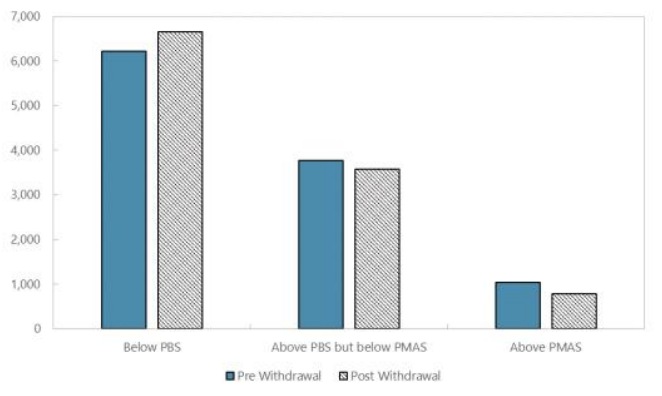

Panel D. Additional APS Costs from Withdrawals by Pensioners, Baseline and Alternative (\% of GDP)

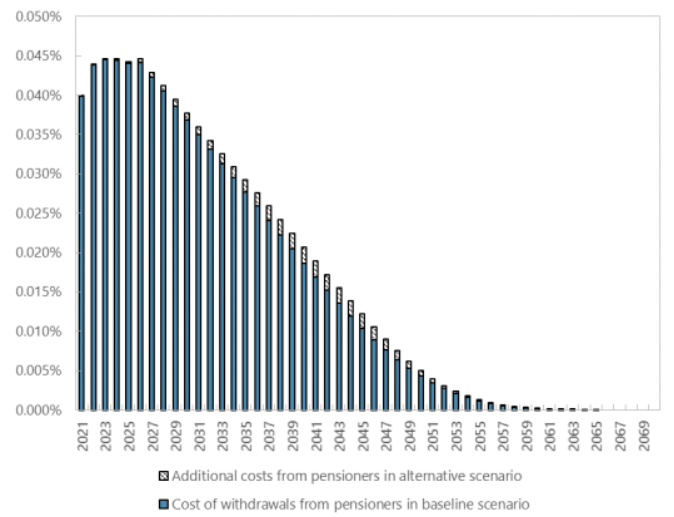

Source: Authors' calculations.

The three rounds of withdrawals will also impact fiscal accounts by lowering tax revenue. Self-funded pensions in Chile are taxable. Thus, the reduction in self-funded pensions is expected to affect tax collection in the future. To quantify foregone revenue, we match current tax brackets to the self-funded pensions pre and post withdrawals. The implicit assumption is that the structure of income tax in Chile will remain constant over the next 40 years. Under this assumption, the government would lose over USD 1.6 billion over 40 years, expressed in net present value 2020 terms. Foregone revenue would peak around 2060 , at approximately 0.008 percent of GDP. An alternative way to quantify loss revenue due to withdrawals is to compute tax losses resulting from the tax exemptions included in the law and gives similar results. If the three withdrawals would have been fully taxable, the tax collection would have increased by over USD 1.8 billion, or 0.7 percent of GDP. 


\section{REFORM OPTIONS}

A. The March Towards Reform

The policy challenge now is to address the shortcoming posed by: infrequent contributions, falling global returns on safe assets, a relatively low mandatory contribution rate, and retirement age not catching up with demographics have dampened pensions for many Chileans. Several actions have been taken over the years, but they may not be sufficient to address the weak pensions, especially going forward

The introduction of the solidarity pillar in the 2008 reform of the system helped to provide a minimum pension and was largely increased in 2019. This was particularly beneficial for women, who have lower contribution densities compared to men on average, retire earlier, and live longer (Barr and Diamond, 2016). Moreover, the change provided incentives for women to work until age 65 , as this is the age when the benefit is paid. At end-2008 the basic pension was 65,470 CLP, about 40 percent of the minimum wage at the time. Following the extraordinary real increase in the PBS level of $10 \%$ in January 2017 , the increase by 50\% announced at end-2019 will bring (when finalized in January 2022 for all pensioners) the minimum guaranteed pension to $50 \%$ of the minimum wage.

\section{Additional support for women was provided in the 2008 reform, Grant per Child} (Bono por Hijo), where the mother is eligible for an additional supplement once she reaches 65 years old. The supplement is equivalent to $10 \%$ of 18 times the minimum wage set in place at the time of birth for each child, plus the average net rate of return on defined contribution pension plans from the date of the birth until the benefit claim. However, this has been deemed insufficient to fully recognize the unpaid caregiving required of the mother and the gap in employment living (Pension Commission, 2015). The Grant per Child paid 360,000 beneficiaries in October 2020, supplementing their monthly pension on average by 9,796 CLP or about US\$12.70.

However, replacements rates remain low and challenges are expected to increase, as an aging population will further strain the current pension system, stretching pension balances over a longer retirement, while the solidarity component will be financed by a slowing workforce. As life expectancy of men and women increases, their accumulated assets at retirement will need to support additional pension years. The population eligible for pension is expected to double from about 3 million in 2021 to 6 million in 2050, adding extra pressure on the solidarity pillar (see Figure 13). The Marcel commission in 2006 proposed a series of parametric changes to strengthen the system and to address equity concerns. The recommendations of the commission laid the foundations for the solidarity pillar, introduced in 2008. More recently, the Bravo commission (2015) proposed further adjustments to the system to account for demographic trends and low contribution rates. The importance of many of these proposed changes have become more prominent in the aftermath of the withdrawals. 




The fundamental solutions reside in enhancing the Chilean pension system, not dismantling it, as it provides many benefits to the economy and society. The financial assets that are managed by the AFPs provide a large stock of savings, with about half of asset under management invested domestically. Moreover, the individual worker has a direct impact on their own pension, providing additional incentives for sustaining employment and therefore contributing to their savings for retirement. Further, the solidarity pillar ensures that almost everyone over the age of 65 receives a pension, close to $95 \%$ (Benavides and Valdés, 2018). The main issue is how to improve the system by adjusting its parameters in terms of contribution rates, retirement age, while trying to increase the density of contribution, so as to give a chance to the pension system to offer adequate pensions. This paper offers some suggestions in that respect.

The latest proposed reform by President Piñera of March 2021, which is a revamp of the January 2020 proposal, aims to increase the contribution rate to 16 percent, expand the coverage of the solidarity pillar, and to add more competition to the system. The additional 6 percent contribution rate will be paid by the employer and managed by a public autonomous body. Half of this increase ( 3 percent) will go to employees' individual pension savings, the other half will go to a collective saving fund. Earnings from the collective saving fund will be used to incentivize contribution to the system by providing additional payments as years of contribution rise. The reform aims to bolster the solidarity pillar, increasing coverage from 60 percent to 80 percent of the population. 
Alternative pension reforms are currently being discussed. The most prominent one would attribute all of the additional 6 percent contribution to the solidarity pillar. This would imply no additional increase in the contribution towards own pension, which would significantly weaken the ability of the system to deliver adequate pensions in the future in the absence of large and growing fiscal costs. Additionally, reforms that would introduce contributions for informal workers (where a share of VAT payments - for individuals that issue a sale bill — or of permit fees — for those who need a permit — would go the individual pension savings account of the consumer) have also been suggested, which would help increase the contribution density.

\section{B. Quantifying the Impact of Reform Proposals}

\section{We explore the impact of different reform scenarios, related to key parameters, on the adequacy of pensions and the reduction of fiscal cost which would arise from a decline} in necessary government support. It quantifies the impact of an increase in the contribution rate to the level in the current proposal. In addition, it studies the impact of a reform package that increases in tandem contribution rates, the retirement age, and the contribution density. Finally, it gauges the cost of a universal basic pension. Importantly, the exercises presented in this section assume immediate implementation of reforms and that these reforms are implemented in a pension system that has undergone the three withdrawals. In practice, reforms may need to be phased-in to address political economy considerations. Thus, our results should be taken as upper bounds of the potential benefits of reforms. ${ }^{23} 24$

\section{An increase in expected replacement rates can be achieved by increasing contribution rates, the retirement age ${ }^{2526}$, or the contribution density. ${ }^{27}$ The interaction of these three}

\footnotetext{
${ }^{23}$ See Annex 4 for additional reform exercises that adjust components of the pension system in isolation.

${ }^{24}$ For further analysis on how different components determine the pension level see Granados et al. (2018a).

25 The baseline assumption is that females retire at 60 and males at 65 , which is close to the effective retirement age for females (61.2) and males (65.3) for those that retired in January 2021.

${ }^{26}$ As shown in Figure 3: Panel B, remaining life expectancy at 65 has increased for males and females, whilst the retirement age has remained constant. For example, in 1990-1995 males at age 65 were expected to live 14.5 more years on average after retirement, which increased to 18.2 more years in 2015-2020. If retirement age increased proportionally to life expectancy from 1990-1995 to 2015-2020 we would expect to see an increase in the retirement age of 3.3 years for women and 3.7 years for men.

${ }^{27}$ The policy analysis abstracts from potential unintended consequences of a change in the system's parameters and, therefore, interpretation of the results should be mindful of these limitations. For example, informality, which can create low contribution densities, could be exacerbated if workers are required to contribute a larger share of their wage to the pension system or contribute to a system with retirement income transfers, weakening the direct link between contributions and final benefits (Piggot et al., 2009). Using data on Chilean households linked with administrative pension system data in a life-cycle model Joubert (2015) finds that raising contribution rates by 5 percentage points increases the size of the informal sector by 12.5 percent for men and 9.3 percent for women. This evidence suggests that when interpreting our results, the reader must be aware of the uncertainty surrounding the exercise.
} 
components on replacement rates is highlighted below in the isoquant exercise of Figure 14. Panel A outlines the possible combinations of contribution rate and retirement age for both male and female workers that allow to obtain a given population average expected replacement rate - that is, the expected replacement rate of all cohorts that are currently contributing to the system. For example, the isoquants show that a population average 40 percent expected replacement rate can be achieved by either increasing the female retirement age to 65 and increasing the contribution rate to 14.5 percent, or by keeping the current contribution rate but increasing the retirement age to 69.5 for all. In addition, Figure 14 shows that an increase in the expected replacement rate can be achieved by either larger changes in one parameter and keeping the other constant, or by changing both param eters incrementally. The relationship between parameters is, however, affected by the contribution density. Indeed, an increase in the contribution density can ease the necessary increase in contribution rates and retirement age to reach a 40 percent population average expected replacement rate. For example, if contribution density increases to 70 percent (from 60 for males and 50 for females) then a population average 40 percent expected replacement rate can be reached with an increase in the retirement age to 67 . For the younger cohorts, those aged 20-25 shown in Panel B, who benefit most from an increase in the contribution rate and contribution density it is possible to reach an expected replacement rate of 70 percent, through an increase in the contribution rate to 18.5 percent and retirement to 70 . If contribution density increases to 70 percent, then the same expected replacement rate ( 70 percent) can be reached assuming an 18.5 percent contribution rate and a retirement age of 66.5 , three and half years earlier than if contribution density did not increase. 


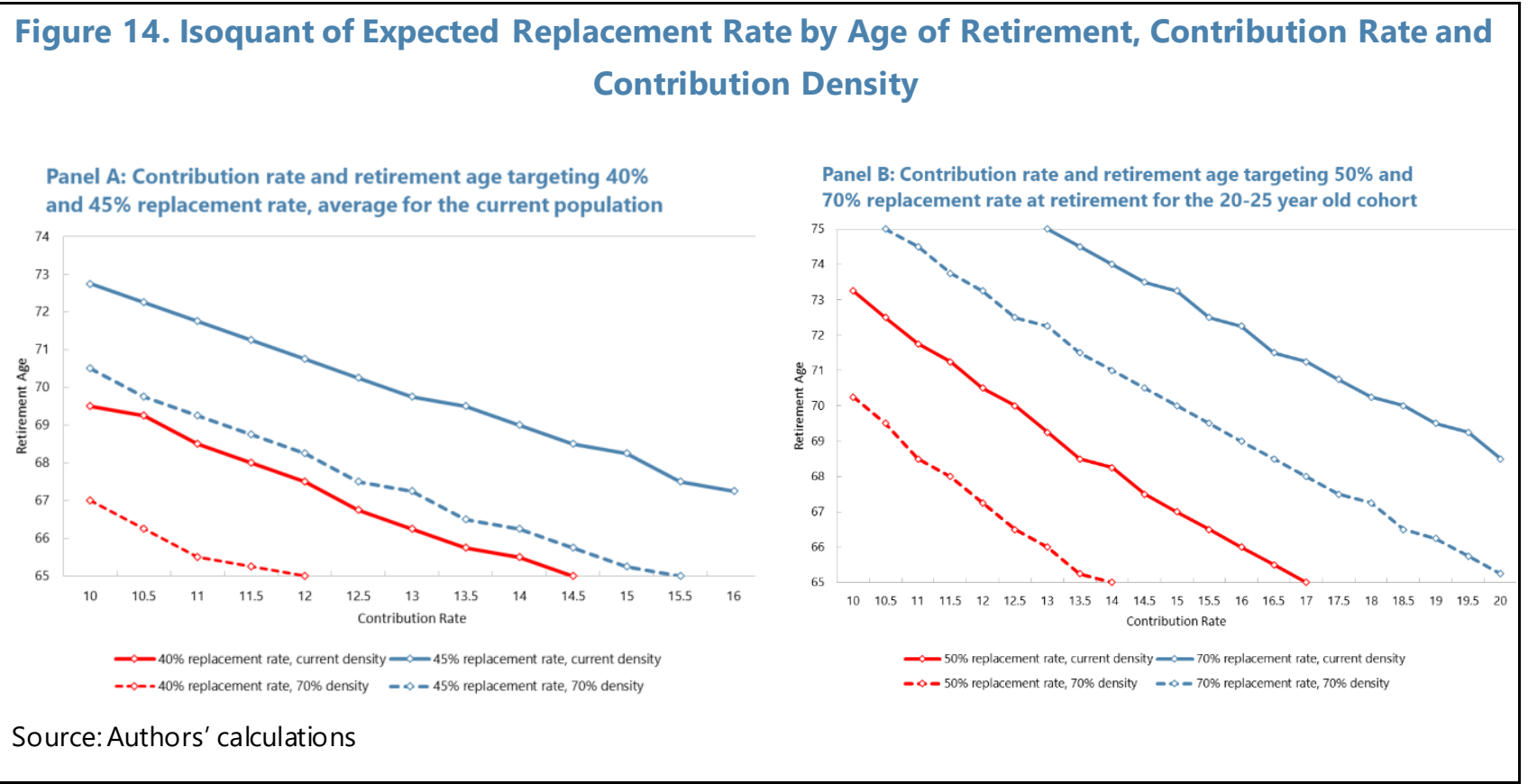

\section{Increasing the mandatory contribution from 10 percent to 13 percent will increase average expected replacement rate from 35 to 37 percent and lower the fiscal cost of the} system. The average expected replacement rate for young affiliates, those aged between 20 and 25, increases from 37 to 45 percent for males and 29 to 33 percent for females after a 3 percentage point increase in the contribution rate (Figure 15). This increase benefits the younger cohorts more as they have more working years ahead of them to contribute at a higher rate and they can benefit from the interest earnt on a larger pension balance. This rise in the mandatory contribution rate lowers the support needed by the government and therefore reduces the fiscal cost of the system (note that due to data constraints the analysis does not account for the additional fiscal costs for the government as an employer associated with its higher contribution to public pensions). However, even for the youngest cohorts an increase in the contribution rate to 13 percent will not bring expected replacement rates above 50 percent, which is the OECD average, motivating the need for a greater increase in the contribution rate. 


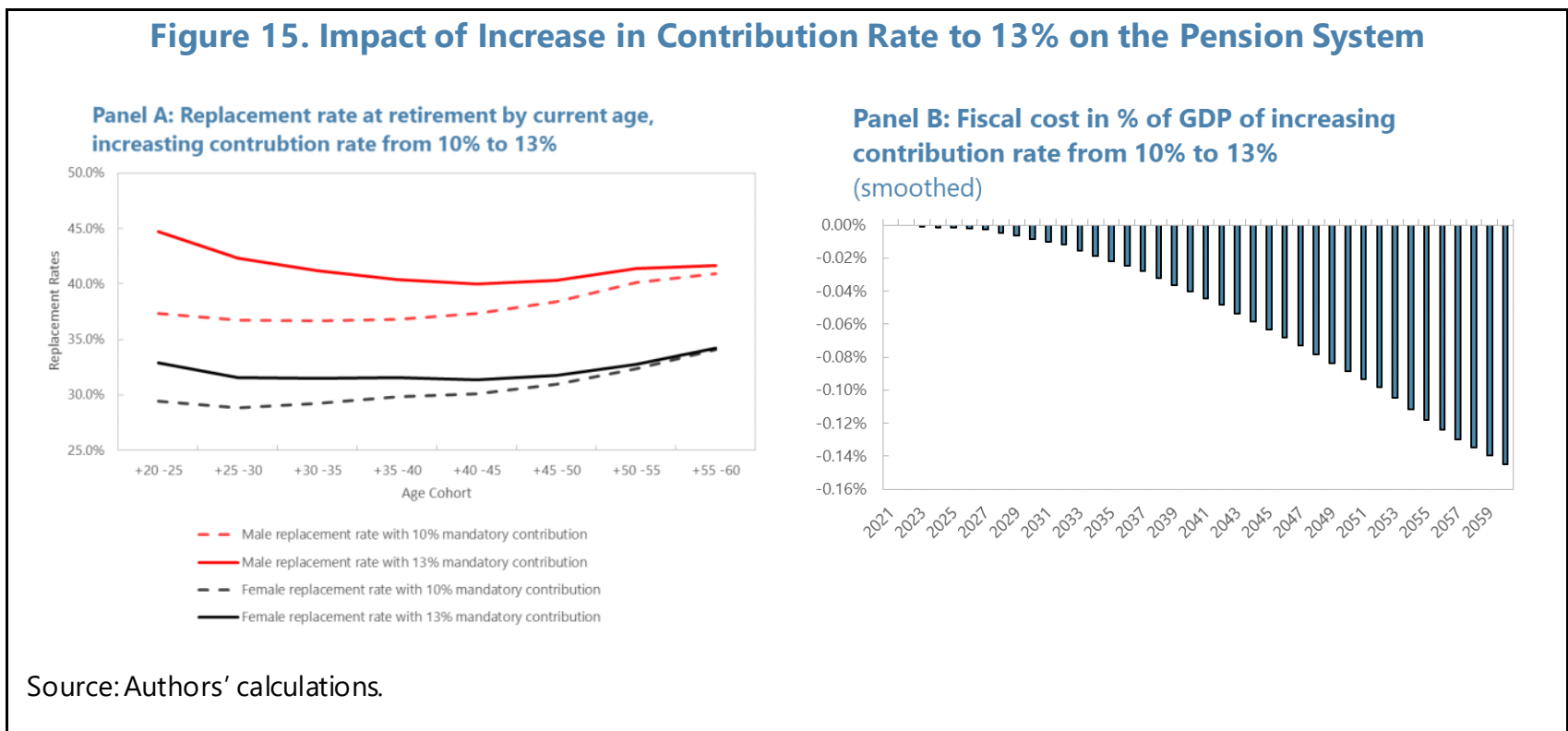

Increasing the contribution rate, retirement age, and contribution density is required to bring the expected replacement rate for the youngest cohorts above 60 percent. As an example of possible combinations of parameters and reforms, increasing the contribution rate from 10 percent to 16 percent, the retirement age to 67 (from 65 for men and 60 for women), and reaching a contribution density of 70 percent (from 60 percent for men and 50 percent for female) would bring the expected replacement rate above 60 percent for the young cohorts (59 for women and 66 for men, Figure 16, panel A), while the expected replacement rate for the average person currently contributing would reach about 50 percent. The combination of measures reduces support needed through the solidarity pillar, lowering the fiscal cost of the pension system, which is expected to be 0.8 percent of GDP lower in 2060 . Such fiscal space could be used to strengthen the solidarity component of pension in a targeted way. Even after equalizing retirement age and contribution density, inequality in expected replacement rates between genders still exists due to differences in life expectancy, which is the principal driver of the difference between young men and women, and current accumulated assets, which causes a larger difference for the older generations.

Notice that the three policies implemented in isolation would have a significantly lower impact on expected replacement rates. Out of the three independent exercises the largest increase in the expected replacement rate at retirement for current affiliates, and particularly the younger cohorts, is due to an increase in the contribution rate from 10 to 16 percent (Figure 16, panel C). This change causes the expected replacement rate to increase from 34 percent to 45 percent for those aged between 20 and 25 , and the population average increases from 35 percent to 40 percent. Increasing the contribution density to 70 percent raises the expected replacement rate for the current pension affiliates from 35 percent to 37 percent, with a larger increase (from 34 percent to 38 percent) for those between the age of 20 and 25 . Changing the retirement age to 67 would increase pensions in three ways: 
allowing contributors to build more assets and accumulate additional returns on past assets, while reducing the number of years the pension is expected to cover. This boosts the expected self-financed portion of the pension at retirement; however, this does not fully pass through into an equivalent increase in expected replacement rates. In our model the increase in real wage, assumed at 1.25 percent, dampens the response in the expected replacement rate, since their pension (self-financed plus additional government support) increases but so does their final wage. The increase in retirement age to 67 , increases the expected ave rage replacement rate by 2 percentage points (from 35 percent to 37 percent).



In addition to the parametric changes discussed above, which are close to those presented in March by the current administration, we quantify the fiscal costs of a universal basic pension (UBP) that is a simplified version of a recent proposal. For example, a proposal from the AFP association would create a UBP that adjusts with the poverty line. ${ }^{28}$ In the exercise below, we study the fiscal impact of a UBP tied to the minimum wage. To be sure, such a design may not necessarily be optimal from a welfare

${ }^{28}$ See https://www.aafp.cl/hay-que-moverse-hacia-una-pension-basica-y-universal/ for further explanation of the universal basic pension proposed. 
point of view. Moreover, it raises political economy concerns since the minimum wage is subject to bargaining between different economic parties. However, from the point of view of our exercise, tying the UBP greatly eases the tractability of the exercise. In addition to tying the UBP to the minimum wage, our ex ercise does not consider eligibility criteria (such as residency requirements that are typically part of UBP schemes) which implies that the costs presented below overstate the true cost of a UBP.

A universal basic pension, providing a fraction of the minimum wage to everyone of eligible pension age (65+ for males and 60+ for females), would reach a cost of anywhere between 2.5 and 4 percent of GDP by 2050 (5 to 8 percent of today's GDP), depending on the choice of parameters. One proposal currently under consideration is the introduction of a universal pension tied to the minimum wage. To quantify the cost of this reform, independently of its source of financing, we consider two scenarios: (i) one where the universal basic pension (UBP) is set today at half real minimum wage and remains constant in real terms, and (ii) one where the UBP is set at 50 percent the real minimum wage and then grows at the same rate as overall wages (assuming a real increase of 1.25 percent). Just to compare to the current solidarity pillar, a UBP of half the minimum wage is roughly equivalent as paying today's PBS value to every retiree, a pension level that falls slightly below the poverty line. The fiscal cost of a UBP of half the minimum wage, 5.6 UF or about US\$ $230,{ }^{29}$ would be approximately 2.5 percent of GDP each year, as the increase in old age population over time is compensated by the decline over time of the minimum pension with respect to GDP per capita (Figure 17, Panel A). This, in turn, would amount to close to 5 percent of GDP in 2020. If the basic pension is assumed to increase with wages, the cost of a UBP of half the minimum wage would increase to over 3.5 percent of GDP by 2050 (close to 8 percent of today's GDP).

Figure 17. Universal Basic Pension

Panel A. Basic universal pension to all eligible as a \% of GDP

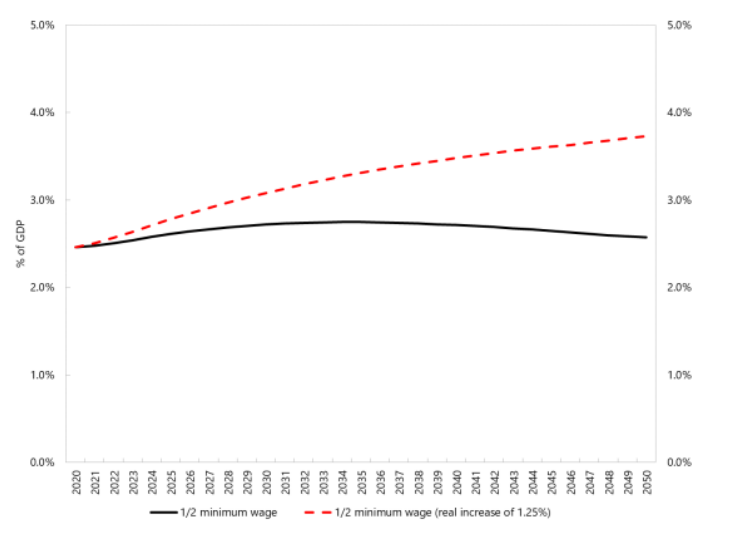

Source: Authors' calculations.
Panel B. Basic universal pension to all eligible as a $\%$ of 2020 GDP

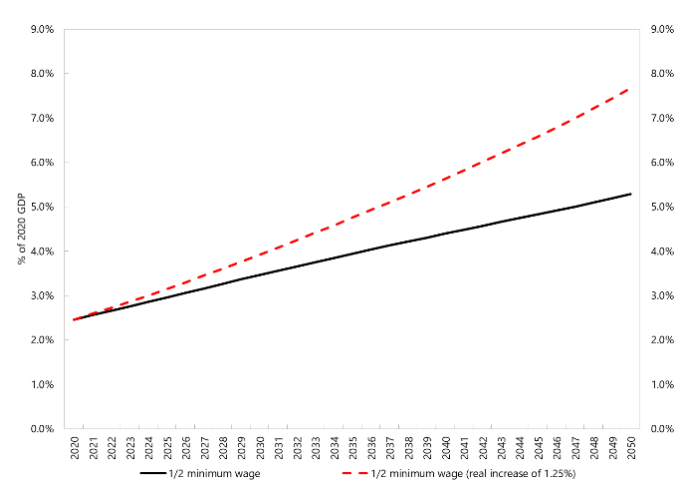

${ }^{29}$ Using the exchange rate at end-February 2021. 


\section{Conclusions}

Chile's pension system served as a blueprint for reform because of its virtues but needs to adapt to changing circumstances. The pension system would have delivered good pensions for people contributing regularly, if demographics and global returns had not changed since its inception. The pension system has also contributed to macroecono mic stability more broadly, by channeling savings into domestic investment and growth, and to developing domestic financial markets. However, the challenges posed by demographic changes - common to many countries - have been calling for years for reforms to sa feguard the system. The system's initial focus on efficiency has been gradually broadened to bring equity into the mix, addressing challenges for poorer people or those that have not been able to contribute regularly. Now, it is time for a more comprehensive overhaul that preserves the sound the core of the system, the self-funded portion, while addressing solidarity needs. Moreover, its parameters should be updated regularly over time to adapt them to changing demographics and global returns.

Replacement rates are low by international standards and are expected to fall further, especially after the three rounds of withdrawals in response to the pandemic. Using internationally comparable data, the paper shows that expected replacement rates in Chile compare poorly to other countries, which is mostly explained by low contribution rates. Moreover, demographic trends, global international conditions, and a system that has not adapted its parameters to keep up with these changes, are expected to contribute to a further decline in the projected replacement rates of future retirees. These problems will likely be compounded by the recent pension withdrawals which exhausted the pension accounts of a large share of participants of the system.

The sharp reduction in self-funded pensions will be buffered by the pension supplement embedded in the solidarity pillar, which in turn will gradually increase the fiscal costs associated with the system. This paper's projections suggest that self-funded pensions would fall, on average, by 21 percent due to the three rounds of withdrawals as of August 2021. This decline, however, will trigger an increase in the government supplement associated with the solidarity pillar, resulting in a lower decline in total pensions ( 7 percent). The increase in government supplements will lead to a gradual increase in fiscal costs relative to current levels. At the peak (near 2060), the withdrawals are expected to lead to an increase of 10 percent in fiscal costs relative to pre-withdrawal levels (or an annual 0.17 percent of GDP). The net present value of these flow of additional costs stands at roughly 3 to 6 percent of 2020 GDP (depending on assumptions), but could be much more in the case of increases in the public solidarity contribution. Further rounds of withdrawals would accentuate these numbers. 
The paper shows that a reform agenda that increases contribution rates, the retirement age, and that improves the contribution density would strengthen the system by improving the adequacy of pensions. An increase in the contribution rate of 6 percentage points devoted to the self-funded pension would increase the expected replacement rate for the average of all current affiliates to 40 percent from 35 percent, and it would increase it to 45 from 34 percent for the 20-25 years old. However, reforms that tackle multiple parameters could achieve similar results with more gradual changes, could have a broader impact across cohorts compared to reforms that focus on a single parameter of the system, and could ease the political economy of reform. For instance, an increase in contribution rates to 16 percent, the retirement age increased to 67 and contribution density to 70 percent will cause expected replacement rates for young people to increase to 59 percent for females and 66 percent for males. It is worth pointing that the contribution density is not a policy parameter per seincreasing it will require implementing policies (labor market, structural and fiscal) that encourage labor market participation and boost job creation in the formal sector. The analysis does not discuss the role of future returns of pension fund investments, which can be influenced not only by global developments, but also by policies affecting competition and portfolio allocations, or imposing performance-related penalties.

Strengthening the self-funded portion of the pension would open fiscal space to enhance also the solidarity component. Indeed, our simulation show that increasing expected replacement rates implies less people in need of the public solidarity pillar at current parameters. For example, the combination of measures highlighted in the previous paragraph will entail a reduction in the fiscal cost of the system by 0.8 percent of GDP in 2060 . Such fiscal space could be used to strengthen the solidarity component of pension in a targeted way.

The analysis also highlights the importance of establishing a periodic review process whereby the parameters of the system are adapted to changes in life expectancy, global returns, and the labor market. It would be valuable to develop a more automated system of updating the key parameters of the pension system such as the contribution rate and the retirement age. This could be done at regular reasonable interval, such as five or 10 years, and specific institutions could be tasked with preparing analysis and proposals. In this respect, the recent pension reform proposal is a step in the right direction, as it proposes that the Social Security Advisory Council reviews demographic, economic and labor market trends every three years to suggest amendments to the system. 


\section{REFERENCES}

Altamirano, A., S. Berstein, M. Bosch, M. García Huitrón, M. L. Oliveri, 2018. “Presente y futuro de las pensiones en América Latina y el Caribe," Inter American Development Bank.

Banco Central de Chile, 2020. Monetary Policy Report, December 2020.

Barrero, A., M. Kirschner, C. Pérez, and A. Sansone, 2020. "Estimación del impacto del Covid-19 en los ingresos de hogares, medidas de apoyo y efectos en el consumo," Minuta asociada con el Recuadro III.1 - IPoM de diciembre 2020

Barr, N. and P. Diamond, 2016. 'Reforming pensions in Chile', Polityka Społeczna, No. 1, 2016,pp. 4-9

Benavides, P. and R. Valdés, 2018. "Pensiones en Chile: antecedentes y contornos para una reforma urgente," Centro de Políticas Públicas, Pontificia Universidad Católica de Chile, Temas de la Agenda Pública No.7,

De la Torre, A. and H. Rudolph, 2018. "The Troubled State of Pension Systems in Latin America," Global Economy and Development at Brookings, Working Paper 112.

Edwards, S., 1996. "The Chilean pension reform: A pioneering program,” Working Paper 5811, National Bureau of Economic Research.

Granados, P., C. Quezada, and X. Quintanilla, 2018. "Determinantes del Nivel de Pensión," Documento de trabajo No 59, Superintendencia de Pensiones de Chile.

Granados, P., F. Toledo, F. Menares, and X. Quintanilla, 2018. "Proyección de los Fondos de Pensiones," Documento de trabajo No 61, Superintendencia de Pensiones de Chile.

IMF, 2021. Chile: Selected Issues. Country Report No. 2021/084.

Joubert, C., 2015. "Pension Design with a Large Informal Labor Market: Evidence from Chile,” International Economic Review, Vol. 56 (2): 673-694.

Lorca, M., 2020. "Effects of COVID-19 Early Release of Pension Funds: The Case of Chile," UNSW mimeo.

OECD, 1998. “The Chilean Pension System,” Working Paper AWP 5.6

OECD (2019), Pensions at a Glance 2019: OECD and G20 Indicators, OECD Publishing, Paris, https://doi.org/10.1787/b6d3dcfc-en.

OECD (2020), Pensions Markets in Focus, OECD Publishing, Paris. 
Piggot, J., Robalino, D., \& Jimenez-Martin, S. (2009). "Incentive effects of retirement income transfers," in Closing the Coverage Gap (Washington, DC: The World Bank Group 2009).

Roldos, J. E., 2007. "Pension Reform and Macroeconomic Stability in Latin America," IMF Working Paper No. 07/108.

Santoro, M., 2017. "Pension Reform Options in Chile: Some Tradeoffs," IMF Working Paper No. 17/53.

Vega, G. (2014). Capital necesario unitario (CNU): Cálculo e introducción del módulo de Stata CNU (No. 57). 


\section{Annex I. The Structure of The ChIlean Pension System}

Chile's pension system consists of two separate parts: a PAYG kept for the military and a defined-contribution system for the civilians. The pension system for the police and armed forces is managed by the Social Security Department of the Chilean Police and the National Defense Social Security Fund. ${ }^{1}$

\section{The current civilian pension system rests on three pillars.}

a. A solidary pillar provided by the government, targeted to the poorest $60 \%$ of the population. This pillar includes a base solidarity pension for individuals with no pension savings, a supplement to individuals with very small pension savings, a Survivor pension in case of death, a Child bonus for mothers, and a Young Workers Subsidy.

The supplement (APS, aporte previsional solidario) is calculated according to the following formula:

$$
A P S= \begin{cases}P B S-\left(\frac{P B S}{P M A S} * \text { PBase }\right) & \text { if } 0 \leq \text { PBase }<P M A S \\ 0 & \text { if } P M A S \leq \text { PBase }\end{cases}
$$

where PBS is the minimum pension (pension básica solidaria), PMAS is the threshold to receive the government supplement, and Pbase is the self-financed pension accruing from the private pension account. Thus, two parameters govern the solidarity pillar: PBS and PMAS. After setting initial levels and after some gradual adjustment, the 2008 law established that PBS and PMAS should remain constant in real terms after 2012 , so the whole solidarity pillar is inflation-indexed. In 2019 there were further adjustment to align the parameters with poverty lines. Adjustments will be gradually implemented over three years (2019-2022). The projection exercise considers two alternative scenarios for the parameters of the solidarity pillar after 2022: a baseline with inflation indexation and an alternative with real growth of 1.25 percent.

b. The second is a mandatory-contribution pillar in which employees contribute to their individual accounts. The mandatory contribution is $10 \%$ of gross salary. These mandatory saving accounts are managed by a few Pension Fund

\footnotetext{
${ }^{1}$ These systems were exempt from the 1981 and 2008 pension reforms. This paper focuses exclusively in the civilian system.
} 
Administrators. Affiliates can choose their AFP, of which there are currently 7 , and subsequently the fund to invest their pension, between the 5 available, which provide an expected return with varying degrees of risk. Contributors and pensioners pay a fee set by AFPs, which is a percentage of the contributors' salary or a percentage of the pensioners' withdrawal.

c. The third is a voluntary saving pillar, with tax benefits offered to encourage participation.

Fees charged by pension funds in Chile rank in the middle of the pack when compared to OECD countries with similar systems. The fees charged by pension funds to their members are difficult to compare across countries as pension systems differ, levels of service are heterogeneous and indirect charges - that are not easily measured - may not be disclosed and accounted for. Figure A1, which uses OECD data on fees as a percentage of total assets, a technique which aids in cross country comparison, shows that Chile's fees as a percentage of total assets is 0.8 , lower than Mexico at 0.9 percent but above Australia and Israel (countries, like Chile, that have a defined contribution system).

Figure A1. Annual fees charged to members as a percentage of total assets, 2019 or latest year available / 1

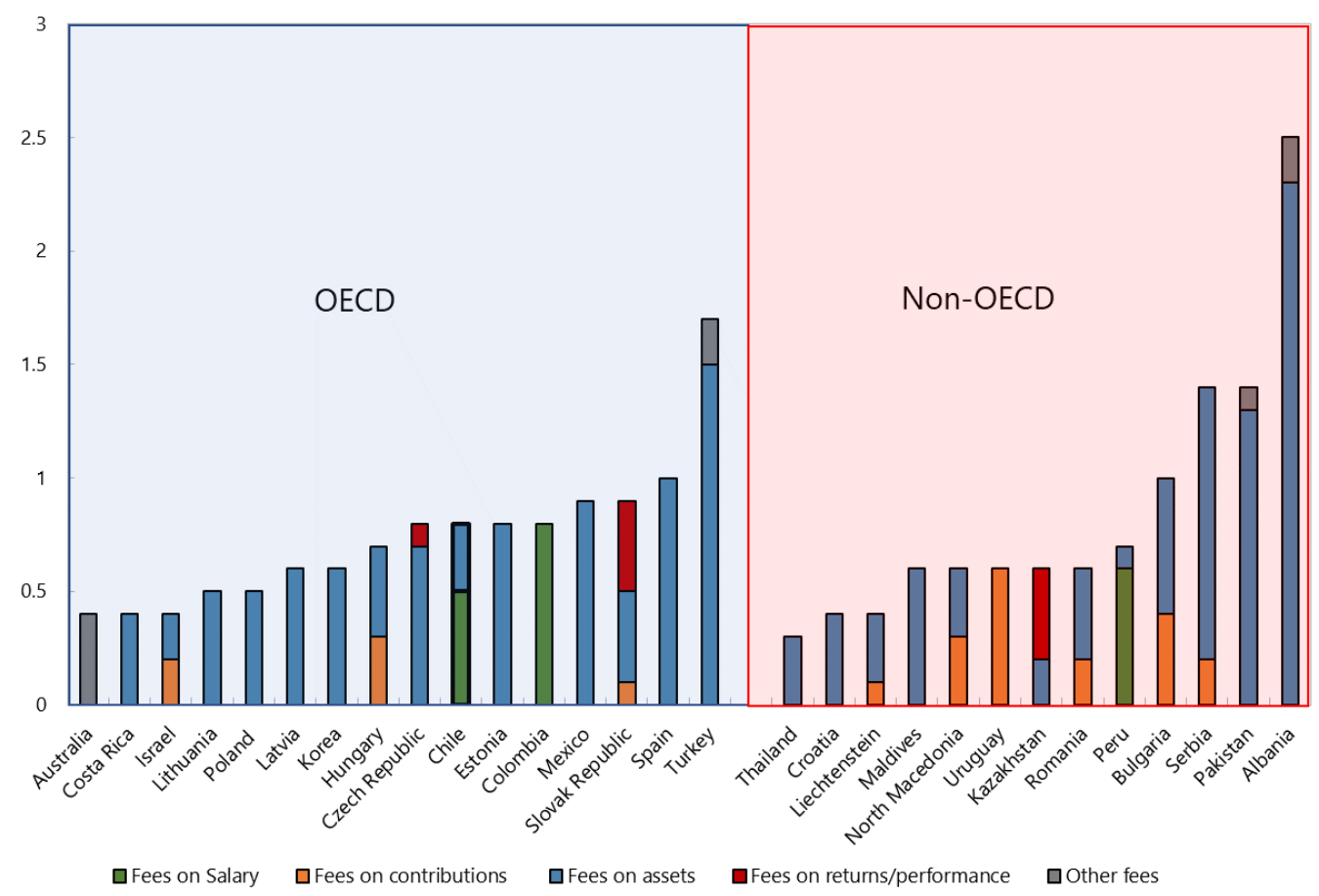

1 / Fee for Australia is uncatego rized.

Sources: Authors' calculations based on OECD (2020). 


\section{AnNeX II. DAta ANd Methodology}

\section{A. International data}

Data used for international comparisons comes from the OECD's Pension at a Glance database (OECD 2019). This includes data on pension contribution rates, fiscal expenditure in pensions, and replacement rates based on the OECD pension model.

\section{B. Chile specific data}

To study details of Chile's pension system, the paper relies on data from the national pension supervisory agency (Superintendencia de Pension, SP). SP provides data of pension affiliates by gender, account balance and age. SP also provides data on wages by age and by account balance, which helps approximate the wage distribution of contributors in the pension system. ${ }^{2}$ Finally, SP provides data on contribution density, the portion of month that an affiliate contributed out of the total eligible contribution periods. The average contribution density for members that retired between January 2017 and December 2020 is $60 \%$ for males and $46 \%$ for females. ${ }^{3}$

\section{Withdrawals}

For the projection exercise, the paper assumes that individuals in each age-gender-account balance cell withdraws from their pension account the maximum amount allowed for each withdrawal. Following the rules in the law, the formula that implements the maximum withdrawal assumption is:

$$
\text { Withdrawal }=\min \left\{\max \left(\min (35, \text { Balance }), \frac{\text { Balance }}{10}\right), 150\right\}
$$

\section{Projecting Pensions: Methodology and Assumptions}

To calculate the expected evolution of replacement rates and fiscal costs, and to assess the impact of withdrawals, we project total pensions and wages that current affiliates will receive at retirement. This is done by combining SP data on balances and wages with assumptions on the real return of pension fund assets, real wage increases, and contribution density. Projections begin in June 2020 data, one month before the $1^{\text {st }}$ withdrawals, so that we can create a theoretical counterfactual.

\footnotetext{
2 This comes from a sample of 47 percent of contributors.

${ }^{3}$ A distribution of contribution density is a ssumed by a ge-gender-account balance to match the gender-wide averages presented in Table A2.1.
} 
The projection of pensions at retirement is done in steps.

1) The first step is to project for each cohort a path for wages from 2020 until the retirement year. This is done by assuming a common growth rate for the wages observed in June 2020. Thus, the wage distribution within cohorts will remain unchanged over time.

2) Once the path for wages is set, we use assumptions on the real return on pension funds and of contribution densities to calculate the private account balances at retirement for each cohort, where cohort is defined as age group and initial pension balance, according to the following formula:

$$
\begin{gathered}
F_{c, n}=P_{c}(1+r)^{n}+A_{c} \sum_{i=1}^{n}(1+w)^{i}(1+r)^{n-i} \\
A_{c}=W_{c, 2020} * 0.1 * D_{c}
\end{gathered}
$$

where $P_{c}$ is the initial account balance (in the current year) by cohort $c, n$ are years until retirement for the cohort, $r$ is the assumed (constant) return on pension funds, $w$ is the common growth rate of wages, and $A_{c}$ is a variable that subsumes the wage in $2020\left(W_{c, 2020}\right)$, the contribution density $\left(D_{c}\right)$, and the mandatory contribution rate of $10 \%$. A distribution of contribution density and wages are assumed by age-genderaccount balance to match the gender-wide averages presented in Table A2.1. For simplicity we assume that contribution density remains constant over time.

3) Once pension account balances at retirement are calculated, we calculate a retiree's monthly private pension as the annuity of its assets at retirement evenly divided over twelve months. Thus, the monthly self-financed pension received by an individual is equal to:

$$
\text { Per month self financed pension }=\frac{\text { Balance }}{C N U \times 12}
$$

where CNU is Capital Necesario Unitario, or capital unit necessary. CNU is the amount of capital that a member requires to finance one pension unit, which takes into account the life annuity rate and the life expectancy of the individual. ${ }^{4}$ For simplicity our exercises calculates the CNU assuming that the new pensioner is single and without children. It is possible to calculate the CNU for members with a spouse, which would increase the CNU as part of the pension will go to the spouse upon death of the individual, lowering the per month self-funded pension.

\footnotetext{
${ }^{4} \mathrm{CNU}$ is explained in detail in a technical note by the Superintendencia de Pensiones by Vega (2014).
} 
To calculate CNU the paper uses the 2014 mortality tables for Chile, for men and women separately. The table provides an adjustment factor that allows for the probability of survival to be calculated for each year into the future. Let $l_{x}$ be the number of people that have survived at age $x$, which can also be understood as the probability of survival at age $x$ and after $t$ years of retirement. The probability of survival at $T=110$ is assumed to be zero and therefore no pensioner lives beyond this age. Given this assumption, CNU is equal to:

$$
C N U=\sum_{t=0}^{T} \frac{\frac{l_{x+t}}{l_{x}}}{(1+i)^{t}}-\frac{11}{24}
$$

4) Having calculated the self-financed pension for each retiree, we calculate the government supplement paid to the individual, as part of the solidarity pillar introduced in 2008, which is a function of the self-financed pension at retirement. Details on the solidarity pillar are deferred to next section.

5) The final step is to compute replacement rates using total pensions (self-financed pensions plus government supplement) and projected wages, and the fiscal costs of the systems, which amount to total supplement payments to beneficiaries of the solidarity pillar.

Parameter assumptions are presented in Table A1 and are chosen as follows:

Real returns on pension accounts: $4.15 \%$ per year. The value is motivated by the July 2018 edition of the projection of the pension system published by the Superintendencia de Pensiones (Granados et al., 2018b). Based on the same report, we assume a rate of $3.36 \%$ for the life annuity rate.

Real wage growth: $1.25 \%$ per year. The number is based on wage growth projections from Chile's budget office (DIPRES). They project that real wage growth will be above $2 \%$ between 2021 and 2026, gradually decreasing to $1.1 \%$ by 2050 . For simplicity, we opted for a constant growth rate which roughly matches DIPRES' profile.

Parameters of the solidarity pillar: The values up to 2022 for the minimum pension (PBS, pensión básica solidaria) and the threshold to receive government support (PMAS, pensión máxima con aporte solidario) are set according to the announcement made in 2019. From 2022 onwards we assume that the two parameters grow at the same rate as wages. 
Parameters of the solidarity pillar: The values up to 2022 for the minimum pension (PBS, pensión básica solidaria) and the threshold to receive government support (PMAS, pensión máxima con aporte solidario) are set according to the announcement made in 2019. From 2022 onwards we present results under two assumptions. The first assumption follows the inflation indexation rule put forward by the 2008 reform. In an alternative scenario we allow PBS and PMAS to grow at the same real rate as wages.

\begin{tabular}{|c|c|c|}
\hline \multicolumn{3}{|c|}{ Table A2.1. Parameter Assumptions } \\
\hline & Baseline & Alternative \\
\hline Real wage growth & $1.25 \%$ & $1.25 \%$ \\
\hline Real return on pension fund assets & $4.15 \%$ & $4.15 \%$ \\
\hline Real interest rate on life annuity & $3.36 \%$ & $3.36 \%$ \\
\hline Average male contribution density & $60 \%$ & $60 \%$ \\
\hline Average female contribution density & $50 \%$ & $50 \%$ \\
\hline Real increase in PBS \& PMAS & $0 \%$ & $1.25 \%$ \\
\hline Mandatory contribution rate & $10 \%$ & $10 \%$ \\
\hline Male retirement age & 65 & 65 \\
\hline Female retirement age & 60 & 60 \\
\hline CPI inflation & $3.00 \%$ & $3.00 \%$ \\
\hline Medium-run nominal GDP growth & $5.50 \%$ & $5.50 \%$ \\
\hline
\end{tabular}




\section{ANNEX III. EXPECTED REPLACEMENT RATES UNDER THE ALTERNATIVE SCENARIO}

Under our alternative scenario, where we assume that the basic solidarity pension and the threshold that defines the cutoff for receiving support (PMAS) increases in real terms by $1.25 \%$ per year - the same as our assumption for real wages. Under this assumption the fall in the expected replacement rates due to an aging population and real wage increases above the rate of increase for the PBS and PMAS is neutralized. For both young males and females in the system their projected replacement rate at retirement is expected to increase by 10 percentage points under our alternative scenario, from about 39 to 50 percent for males and 30 to 42 percent for females. The cause of this rise is the increase in the government supplement received by affiliates, leading to a higher fiscal cost of the system in the medium-term.

Figure A3.1. Expected Replacement Rates under our Alternative Scenario

Panel A: Male expected replacement rate at retirement by current age, pre and post withdrawals



Source: Authors' calculations. 
Figure A3.1. Expected Replacement Rates under our Alternative Scenario (Continued)

Panel B: Female expected replacement rate at retirement by current age, pre and post withdrawals

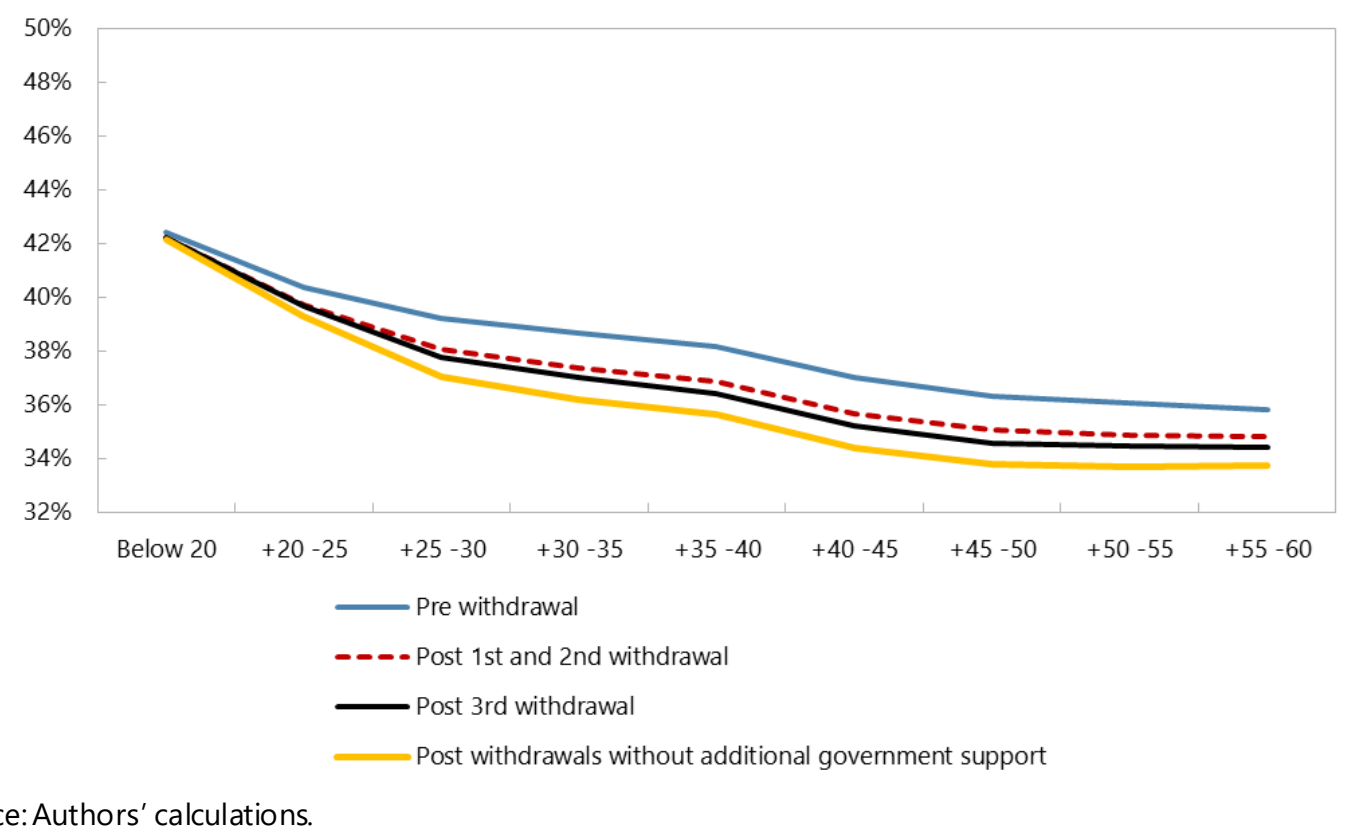

CInternational Monetary Fund. Not for Redistribution 


\section{ANNEX IV. INDIVIDUAL REFORM SCENARIOS}

This annex presents further details of the three reform scenarios presented in Figure 16 of the main text. Increasing the contribution rate from $10 \%$ to $16 \%$ increases the self-financed balance of workers at retirement by about $59 \%$ for the cohort currently between the ages of 20 and 25 in the system and lowers the government support required to support pension benefits. Increasing the mandatory contribution rate, which causes a greater share of employee's wages to be deposited in their individual pension accounts, substantially increases the savings accumulated at retirement age. Increasing the mandatory contribution rate, which benefits younger workers, who have more time to contribute until retirement, will increase their expected replacement rate to 46 percent (53 percent for men and 36 percent for females) for those aged between 20 and 25 . The impact of this reform on the adequacy of pensions will be lower for affiliates closer to retirement, however, it is still expected to increase their individual balances at retirement. An increase in the self-financed component of the pension means that the government, which follows the complementary supplement formula outlined in the 2008 pension reform, is required to subside a smaller share of the average final pension received and a greater proportion of the population will exit the PMAS threshold. The higher mandatory contribution rate is expected to gradually lower the fiscal cost of the pension system, reducing the cost by 0.3 percentage points of GDP by 2060 .

\section{Figure A4.1. Impact of increase in contribution rates on the pension system}

Panel A: Expected replacement rate at retirement by age cohorts, increasing contribution rate from $10 \%$ to $16 \%$

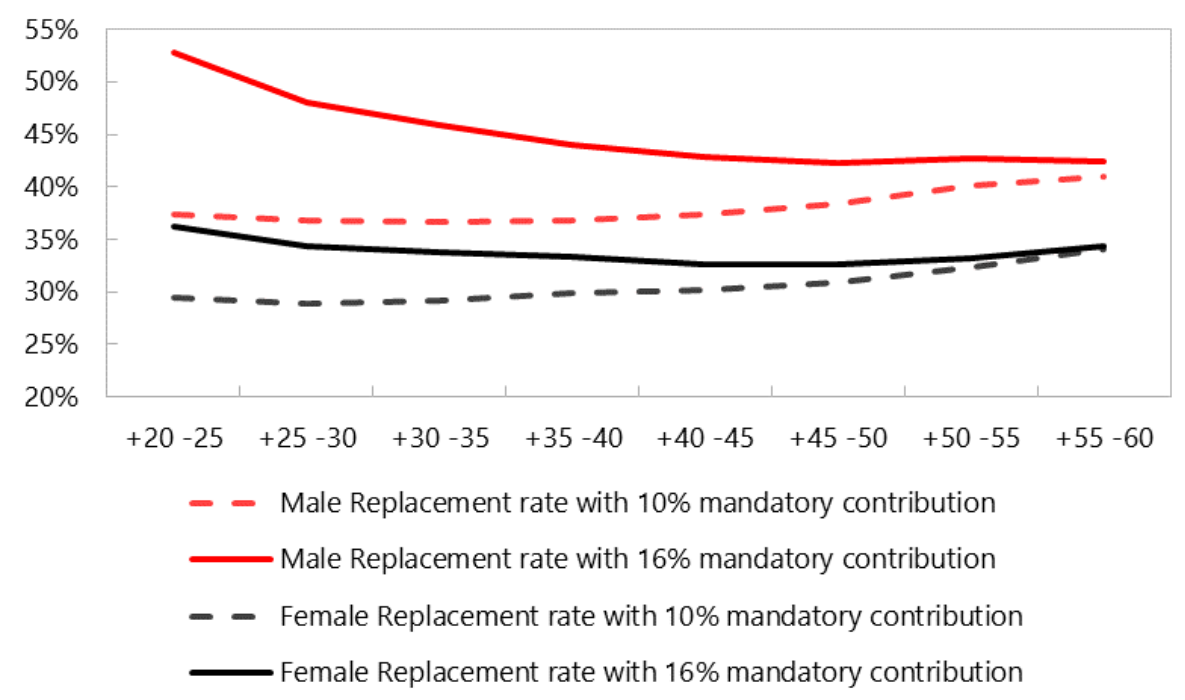

Source: Authors' calculations. 


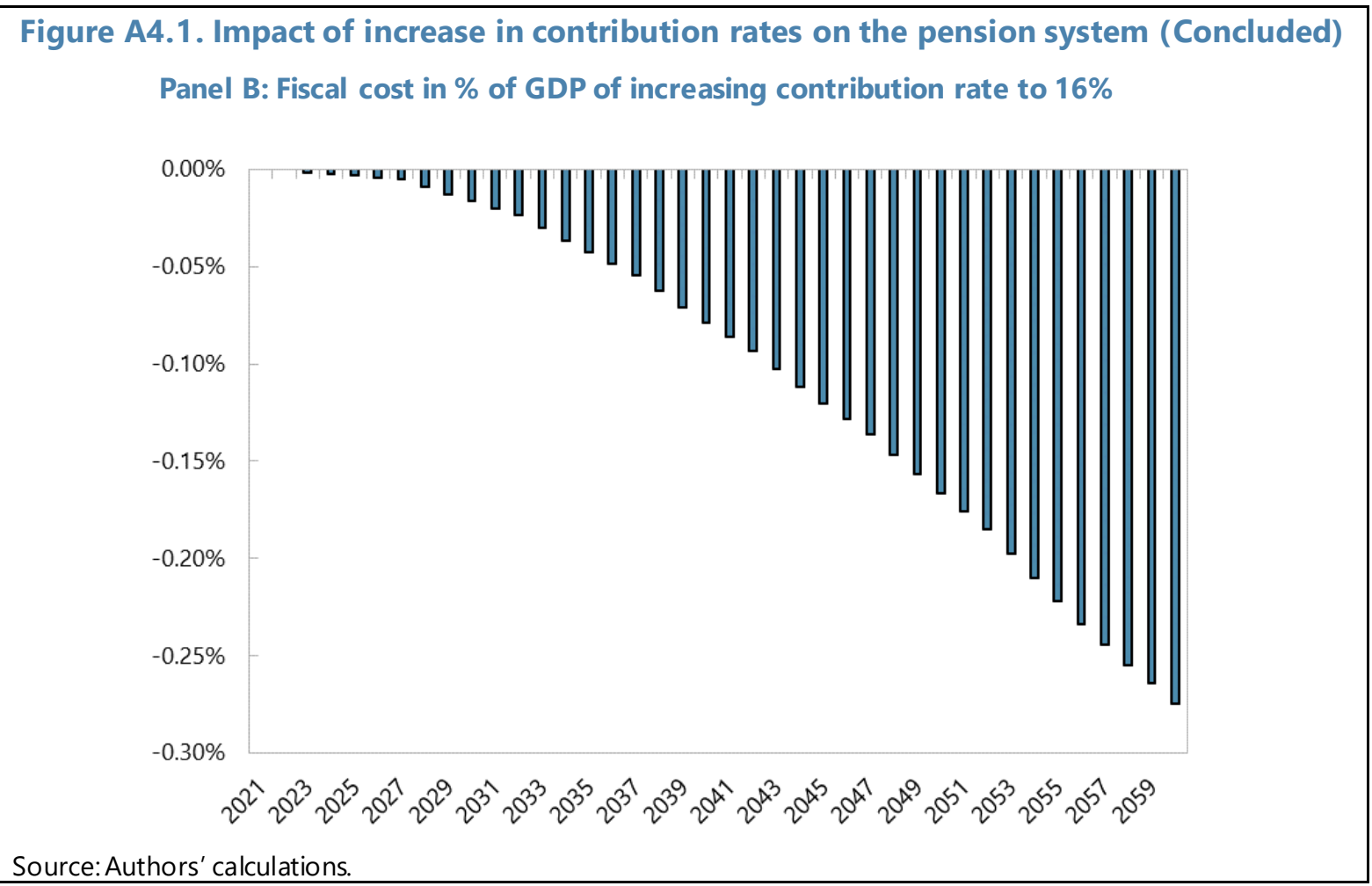

Increasing the average contribution density greatly benefits the younger cohorts, as they can accumulate larger pensions at retirement. The current average contribution rate of males, about 60 percent, and females, slightly below 50 percent, is low by international standards and is one cause of low pensions for retirees. Increasing the contribution rate to 70 percent, increases the expected replacement rate of both men and women. The expected replacement rate for young males increase from about 37 percent to 41 percent, and from about 29 percent to 34 percent for young females. This would also lead to a lower fiscal cost for the government, by 0.10 percent in 2060 . Further improvements in expected replacement rates can be made if the contribution density would increase above 70 percent. However, increasing contribution density, which is intrinsically linked to informality, is not a standard pension reform policy and would be better addressed through structural reforms to the economy that would lead to sustained employment in the formal sector. 
Figure A4.2. Impact of increase in contribution density on expected replacement rates

Panel A: Expected replacement rate at retirement by age cohorts, increasing contribution density to $70 \%$

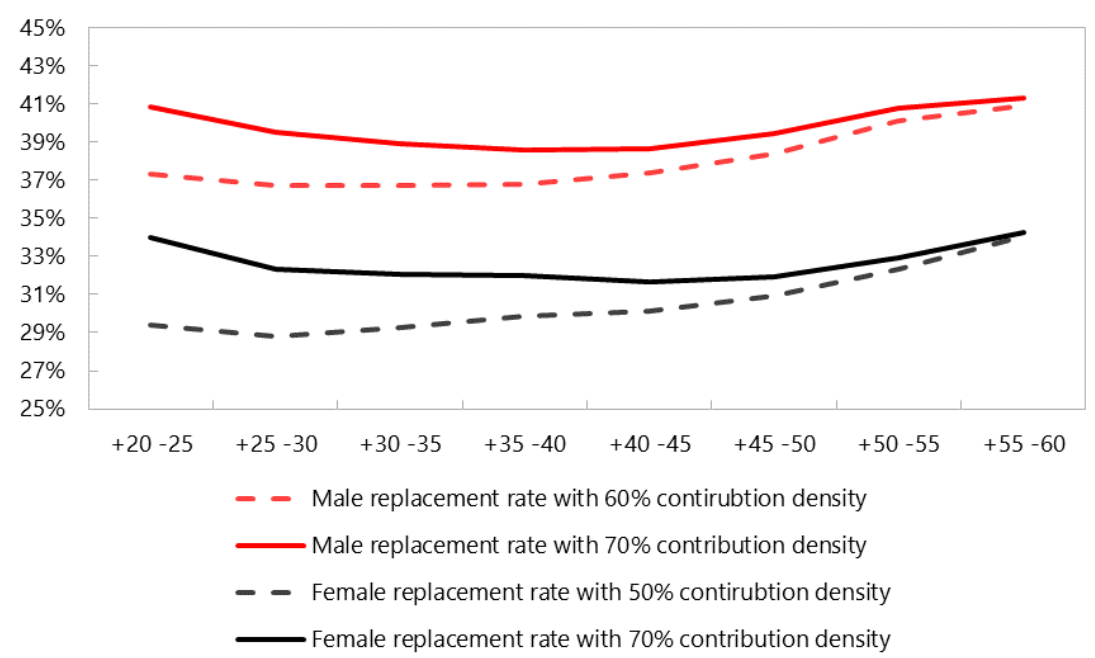

Panel B: Fiscal cost in \% of GDP of increasing contribution density to $70 \%$

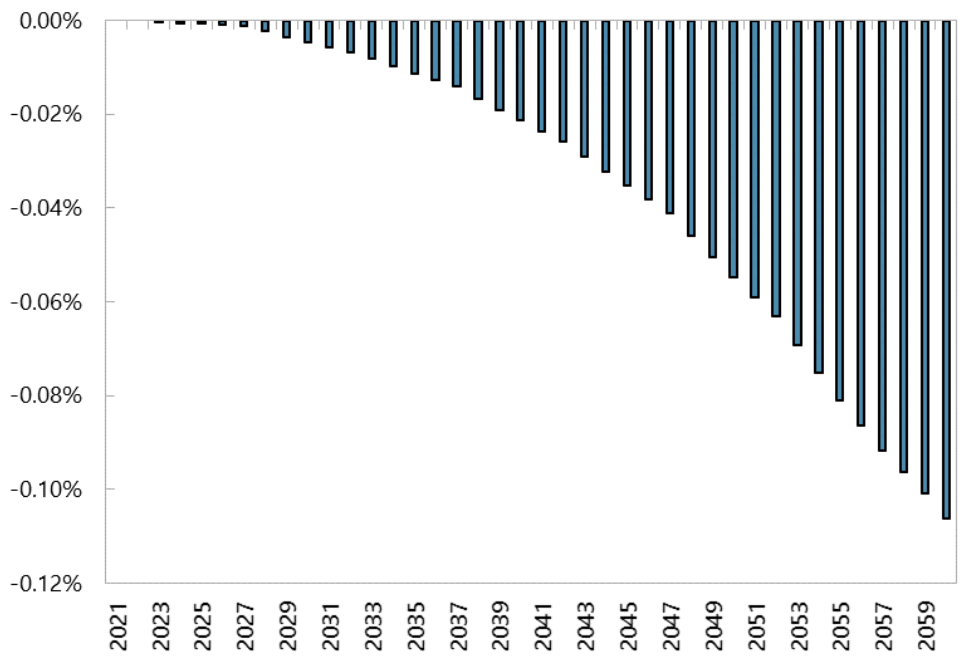

Source: Authors' calculations.

An increase in the retirement age for both males and females to 67 increases the expected replacement rate by 2 percentage points on average for males and 3 percentage points for females. Increasing the retirement age to 67, from 60 for females and 65 for males, increases the number of working years and therefore the time to contribute to their pension account. Moreover, a later retirement date reduces the number of years the pensioner will need to spread their savings over, allowing for a more adequate pension on average. Panel A of Figure A4.3 outlines the substantial boost to self-financed pensions that increasing the retirement age accomplishes, especially for women. However, this increase does not fully pass through into an equivalent increase in expected replacement rates. In our model the increase in real wage, assumed at 1.25 percent, dampens the response in the 
expected replacement rate, since their pension (self-financed plus additional government support) increases but so too does their final wage. Moreover, for women the self-financed component makes up only 35 percent of their total pension payments, limiting the overall boost to their expected replacement rates. Although the retirement age of males and females are equated the expected replacement rates remain unequal, as a lower contribution density ( 50 for women and 60 for men) is assumed, and women are expected to live longer (stretching their pension further). The increase in working years bolsters the self-financed component of the pension, which lowers the solidarity support required by the government and therefore lowers the fiscal cost of the system. Since the majority of pensioners that are supported by the solidarity pillar are women, and we are assuming a 7 -year increase in their retirement age, this has a particularly significant impact on the fiscal cost of the pension system.

Figure A4.3. Impact of increasing retirement age to 67

Panel A: Increase in self-financed pension due to increasing retirement age to 67

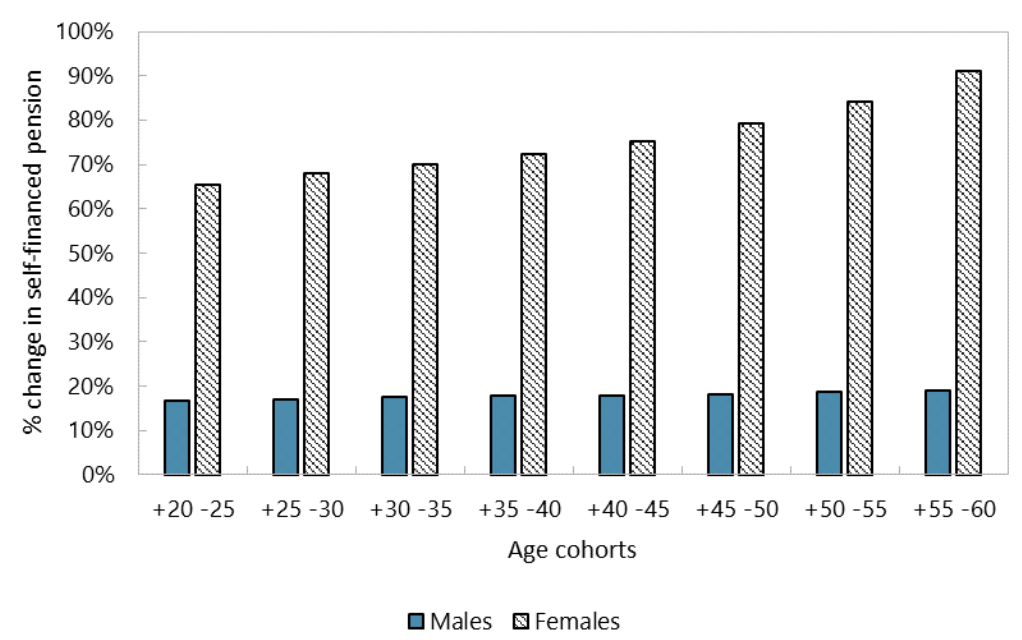

Panel B: Expected replacement rate at retirement by age cohorts, increasing retirement age to 67

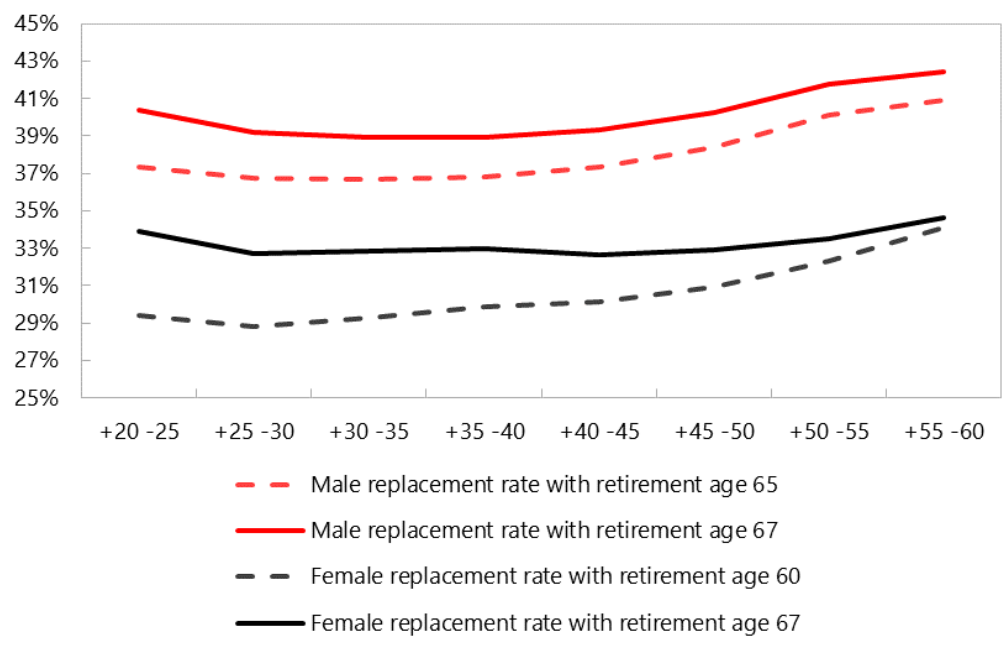


Figure A4.3. Impact of increasing retirement age to 67 (Concluded) Panel C: Fiscal cost in \% of GDP of increasing retirement age to 67



Source: Authors' calculations. 